\title{
Hydrogen Production via a Commercially Ready Inorganic membrane Reactor
}

Semi-Annual Technical Progress Report

Reporting Period: October 1, 2004 to March 31, 2005

Paul K. T. Liu

Project Director

August 23, 2005

PREPARED FOR THE UNITED STATES

DEPARTMENT OF ENERGY

Under Cooperative Agreement

No. DE-FC26-03NT41852

By

MEDIA AND PROCESS TECHNOLOGY, INC.

1155 William Pitt Way

Pittsburgh, PA 15238 


\section{Disclaimer}

This report was prepared as an account of work sponsored by an agency of the United States Government. Neither the United States Government nor any agency thereof, nor any of their employees, makes any warranty, express or implied, or assumes any legal liability or responsibility for the accuracy, completeness, or usefulness of any infor mation, apparatus, product, or process disclosed, or represents that its use would not infringe privately owned rights. Reference herein to any specific commercial product, process, or service by trade name, trademark, manufacturer, or otherwise does not necessarily constitute or imply its endorsement, recommendation, or favoring by the United States Government or any agency thereof. The views and opinions of authors expressed herein do not necessarily state or reflect those of the United States Government or any agency thereof. 


\section{$\underline{\text { Abstract }}$}

Single stage low-temperature-shift water-gas-shift (WGS -LTS) via a membrane reactor (MR) process was studied through both mathematical simulation and experimental verification in this quarter. Our proposed MR yields a reactor size that is 10 to $>55 \%$ smaller than the comparable conventional reactor for a CO conversion of 80 to $90 \%$. In addition, the $\mathrm{CO}$ contaminant level in the hydrogen produced via MR ranges from 1,000 to $4,000 \mathrm{ppm}$ vs 40,000 to $>70,000 \mathrm{ppm}$ via the conventional reactor. The advantages of the reduced WGS reactor size and the reduced CO contaminant level provide an excellent opportunity for intensification of the hydrogen production process by the proposed MR. To prepare for the field test planned in Yr III, a significant number (i.e., 98) of full-scale membrane tubes have been produced with an on-spec ratio of $>76 \%$ during this first production trial. In addition, an innovative full-scale membrane module has been designed, which can potentially deliver $>20$ to 30 $\mathrm{m}^{2} /$ module making it suitable for large-scale applications, such as power generation. Finally, we have verified our membrane performance and stability in a refinery pilot testing facility on a hydrocracker purge gas. No change in membrane performance was noted over the $>100 \mathrm{hrs}$ of testing conducted in the presence of $>30 \% \mathrm{H}_{2} \mathrm{~S},>5,000$ ppm $\mathrm{NH}_{3}$ (estimated), and heavy hydrocarbons on the order of $25 \%$. The high stability of these membranes opens the door for the use of our membrane in the WGS environment with significantly reduced pretreatment burden. 


\section{TABLE OF CONTENTS}

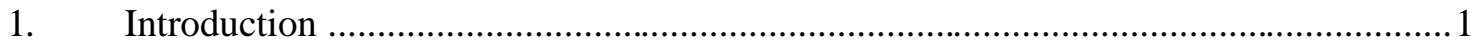

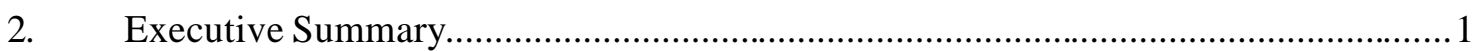

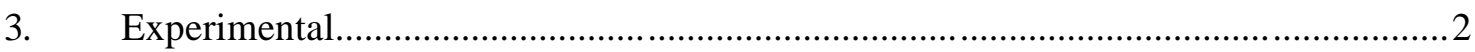

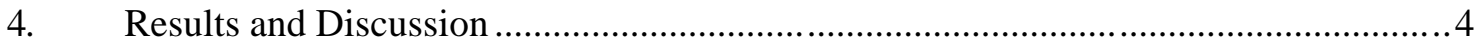

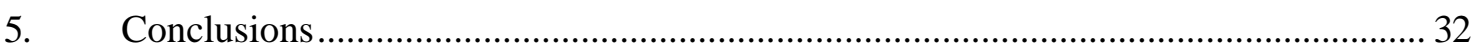

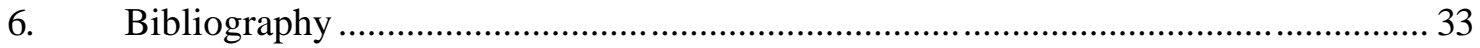

7. Acronyms 


\section{List of Graphical Materials}

\section{Figures}

Figure 1 Dry mill corn starch to ethanol process

Figure 2 Conventional large-scale production of anhydrous motor fuel ethanol.

Figure 3 Total flux vs. water concentration in the feed for dehydration of isopropanol..........

Figure 4 Water concentration in the permeate vs. water concentration in the feed for dehydration of isopropanol

Figure 5 Arrhenius plots of the water permeation rate through zeolite membrane

Figure 6 Module Configuration

Figure 7 Gas Stream Compositions and Stage Cut and H2 Recovery for the VGO Hydrocracker Pilot Test...... 


\section{Introduction}

The advantage of using the low temperature shift (LTS) (vs the high temperature shift (HTS)) reactor is its high degree of conversion at this low temperature due to the exothermic reaction of WGS. In the convent ional WGS process, HTS is performed as a first stage reactor to convert a majority of the $\mathrm{CO}$, taking the advantage of the enhanced reaction kinetics at a high temperature (i.e., $350-450^{\circ} \mathrm{C}$ ). Then the residual $\mathrm{CO}$ is sent to the LTS as a polishing step to reduce $\mathrm{CO}$ to the level of $=1 \%$. Based upon the enhanced efficiency delivered by the MR via the in-situ removal of the reaction products, it is possible to achieve the $\mathrm{CO}$ conversion nearly completely via the single stage, LTS. Thus, the process intensification objective can be fulfilled since (i) the HTS reactor is no longer needed, and (ii) the enhanced LTS is sufficient for CO conversion. For our present study, we focus on the use of the conventional $\mathrm{Cu} / \mathrm{Zn}$-based catalyst. Other catalysts, such as sulfide-based, will be investigated in the $2^{\text {nd }}$ half of this project.

A mathematical model has been developed to predict the performance of the proposed membrane reactor for water gas shift reaction (WGS), so that the operating conditions can be optimized. In addition, a mathematical model can guide us to tailor a suitable membrane, in terms of permeance and selectivity, to commensurate with the existing commercial catalyst performance. Oxygen blown gasifier off-gas was used as an example in this study. In addition to the material balance check performed in Sec. 1, the prediction from the mathematical model was compared with the experimental results to validate the model prediction.

To prepare for the field test planned for Yr III at the PFDU, we have been actively pursuing the manufacturing of the full size membrane element (30"L) and the conceptual design of the full-scale module. This production run would produce enough inventory for the membrane requirement for the field test. More importantly, based upon the on-spec ratio of the full-scale membrane production run, the product cost can be estimated realistically.

This semi-annual report summarizes our activities in the above areas.

\section{Executive Summary}

Single stage low-temperature-shift water-gas-shift (WGS-LTS) via a membrane reactor (MR) process was studied through both mathematical simulation and experimental verification in this quarter. Using the kinetic parameters experimentally obtained by us, we are able to validate the mathematical model via the bench-top experimental results. Although the thermodynamic conversion of CO could be as high as $\sim 90 \%$ in the LTS range, our proposed MR yields a reactor size that is 10 to $>55 \%$ smaller than the comparable conventional reactor for a CO conversion of 80 to $90 \%$. In addition, the $\mathrm{CO}$ contaminant level in the hydrogen produced via MR ranges from 1,000 to 4,000 ppm vs 40,000 to $>70,000 \mathrm{ppm}$ via the conventional reactor. The advantages of the reduced 
WGS reactor size and the reduced CO contaminant level provide an excellent opportunity for intensification of the hydrogen production process by the proposed MR

To prepare for the field test planned in Yr III at the PFDU facility, we have focused in this quarter on (i) full-scale membrane production, (ii) full scale membrane module design and fabrication, (iii) membrane performance stability testing under harsh field environment, (iv) thermal management, and (iv) assessment of the benefit of using our proposed MR at the PFDU facility. A significant number (i.e., 98) of full-scale membrane tubes have been produced with an on-spec ratio of $>76 \%$ during this first production trial. An innovative full-scale membrane module has been designed, which can potentially deliver $>20$ to $30 \mathrm{~m}^{2}$ /module making it suitable for large-scale applications, such as power generation. Finally, we have verified our membrane performance and stability in a refinery pilot testing facility on a hydrocracker purge gas. No change in membrane performance was noted over the $>100$ hrs of testing conducted in the presence of $>30 \% \mathrm{H}_{2} \mathrm{~S},>5,000 \mathrm{ppm} \mathrm{NH}_{3}$ (estimated), and heavy hydrocarbons on the order of $25 \%$. The high stability of these membranes opens the door for the use of our membrane in the WGS environment with significantly reduced pretreatment burden. The activities on (i) reducing the pretreatment requirement and (ii) improving the WGS efficiency at the PFDU facility are continuing; their results will be reported in the next semi-annual report.

\section{Experimental}

\subsection{Mathematical Model, Kinetic Parameters and Feed Composition.}

\subsection{1. $\quad$ Mathematical Model and Kinetic Parameters}

A mathematical model can be developed based upon the material balance coupled with the reaction rate equations. The model, once developed, can then be solved numerically via the finite difference method. A steady state condition with concentration profile along the axial direction of the reactor is assumed here.

\subsection{2. $\quad$ Feed Composition.}

The feed composition is represented by $\mathrm{CO}: \mathrm{H}_{2}: \mathrm{CO}_{2}: \mathrm{H}_{2} \mathrm{O}=1.00: 0.70: 0.33: 1.10$. The water content was calculated based upon 1.1 times of the stoichiometric requirement for the complete conversion of $\mathrm{CO}$ present. This $\mathrm{H}_{2} \mathrm{O}$ to $\mathrm{CO}$ ratio, i.e., 1.1, is deemed to be minimal requirement for WGS. According to our calculations, assuming that the off-gas is available at $\sim 1,200^{\circ} \mathrm{C}$, quenching the reaction with water to the $1.1: 1$ ratio would yield a stream temperature of $\sim 600^{\circ} \mathrm{C}$. Hence, additional cooling is necessary to chill the stream to the LTS range of $\sim 200^{\circ} \mathrm{C}$ and can be accomplished via indirect cooling. The indirect cooling allows one to recover the heat for other purposes. The advantage of the indirect cooling at a lower temperature is the use of less exotic heat exchanger material. From the reaction kinetic standpoint, the use of the minimum steam: $\mathrm{CO}$ ratio here is 
justified versus 3:1 in the conventional reactor, since the improved efficiency of the proposed MR compensates for the rate loss.

\subsection{Comparison of Packed Fixed-bed Reactor (PFR) vs Membrane Reactor (MR) for WGS-LTS (based upon simulation).}

The equilibrium conversion of $\mathrm{CO}$ for the LTS reaction is very high. For instance, about $89.9 \%$ conversion at $250{ }^{\circ} \mathrm{C}$ with the composition of $\mathrm{CO}: \mathrm{H}_{2}: \mathrm{CO}_{2}: \mathrm{H} 2 \mathrm{O}=1: 0.70: 0.33: 1.1$. Thus, instead of the comparison of the conversion levels in our study the comparison was made as follows:

Demonstrate the enhanced reaction rate at LTS with the use of the MR. W/F (gm cata

- $\quad$ lyst/g mol CO/hr) was used as a parameter to determine the \% CO conversion as a function of W/F. Essentially the reactor size requirement to reach a given level of $\mathrm{CO}$ conversion is compared between MR and PFR.

- Determine the hydrogen purity of the product produced from MR vs PFR.

\subsection{Experimental Verification of Mathematical Model}

The mathematical model developed was verified by experimental study performed in a laboratory scale membrane reactor. The experiment was held at $250^{\circ} \mathrm{C}$ and $\mathrm{P}_{\text {feed }}=3 \mathrm{bar}$ and $\mathrm{P}_{\text {perm }}=1$ bar. Feed Composition selected is $\mathrm{H}_{2}: \mathrm{H}_{2} \mathrm{O}: \mathrm{CO}: \mathrm{CO}_{2}=4: 1.1: 1: 0.01$. The $\mathrm{CO}$ conversions at the exit of both feed and permeate sides were measured to verify the mathematical model prediction.

\subsection{Full Scale Membrane and Module Production}

The full-scale membranes were prepared according to the protocol we developed previously. Once prepared, the membrane permeances were determined at $120^{\circ} \mathrm{C}$ for its $\mathrm{He}, \mathrm{H}_{2}$, and $\mathrm{N}_{2}$ permeance. Nitrogen was used as a surrogate gas for $\mathrm{CO}$. In addition, we packaged the individual tubes together as a bundle using ceramic potting material. The bundle will then be used for future field test.

\section{5. $\quad$ Simulation of WGS Under Field Operating Condition}

Our simulation shown in Sec. 3.3 demonstrates the advantages of a membrane reactor under a bench-top operating condition. Further, the simulation was experimentally verified at the condition which can be easily accomplished in our existing laboratory environment. In this section, we attempted to simulate the process close to the field operating condition; thus, the anticipated improvement via the use of the proposed membrane reactor can be quantified. Details of the simulation parameters are presented below:

Permeate Side Purge Ratio...In the field operation, some purging of the permeate side can provide enhanced membrane productivity, particularly if steam generated from low quality waste heat is used. Thus, our first task in this section is to evaluate the effect of 
purge flow rate. Although the purge is accomplished by low pressure gas stream, from the cost minimization standpoint, it is beneficial to minimize the purge rate. Our simulation selected purge rates of 10 to $40 \%$ of the feed rate to study the effect on $\mathrm{CO}$ conversion.

Reactor Pressure...In our simulation of a lab scale reactor, the feed side pressure was kept low at about 3 to 5 bar. The actual gasifier off-gas could deliver 30 to 80 bar pressure or even higher. Thus, the effect of pressure on the $\mathrm{CO}$ conversion and the contaminant level is a critical aspect of our simulation of the field scale reactor. In this report, we study the operation at a much higher pressure, i.e., 15 and 3 bar feed and permeate side pressures, respectively.

Permeance and Selectivity...Also our membrane manufacturing development has made significant progress recently as detailed in Sec. 5. Based upon the performance data on these full scale membranes, $\mathrm{H}_{2}$ permeance $=4 \mathrm{~m}^{3} / \mathrm{m}^{2} / \mathrm{hr} /$ bar at $250^{\circ} \mathrm{C}$ (projected from the data at $120^{\circ} \mathrm{C}$ shown in Figure 5) and $\mathrm{H}_{2} / \mathrm{CO}=100$ appears achievable. Thus, these performance data were used in our simulation in this section.

Field Test Under Harsh Environment...While we are currently working on the opportunity to test the WGS from coal based utility plant in Yr III, the membrane developed from this project was field tested at ChevronTexaco's refinery pilot test facility for hydrogen recovery from a refinery waste stream (hydrocracker purge gas). More importantly this test stream provided an opportunity to evaluate the membrane stability operated under a harsh industrial environment, such as the presence of sulfur, ammonia and heavy hydrocarbons, which are commonly encountered in coal gasification applications.

Membrane Challenge Test...Finally our hydrogen selective membrane was subject to a challenge test at the end of this field test. The membrane was exposed to dead-end gas separation (i.e., exposed to the enriched contaminants) for about 17 hours in the field. The permeance was recorded before the challenge test, at the end of the dead-end test, and after the regeneration to determine the degree of permeance poison and its restoration.

\section{Results and Discussion}

\subsection{Mathematical Model, Kinetic Parameters and Feed Composition}

The mathematical model (see Appendix I) has been developed during this reporting period. To verify its accuracy, a material balance check was performed numerically. The results presented in Appendix II validate the model. This model, along with the kinetic parameters obtained experimentally, has been employed for comparison between the packed bed and the proposed membrane reactor for a single stage WGS-LTS reaction. 
For all the calculations performed here we utilized the kinetic equations for WGS, described as follows [Ref. 1.]

$$
\begin{aligned}
& r=A \cdot \exp \left(-E_{a} / R T\right) \cdot \frac{P_{C O} \cdot P_{\mathrm{H}_{2} \mathrm{O}}^{1.4}}{P_{\mathrm{CO}_{2}}^{0.7} \cdot P_{\mathrm{H}_{2}}^{0.9}} \frac{1}{P_{t}^{0.4}}(1-\beta) \\
& \beta=\frac{1}{K_{g}} \frac{\left(P_{\mathrm{CO}_{2}} \cdot P_{\mathrm{H}_{2}}\right)}{\left(P_{\mathrm{CO}} \cdot P_{\mathrm{H}_{2} \mathrm{O}}\right)} \\
& K_{g}=\frac{P_{\mathrm{CO}_{2}} \cdot P_{\mathrm{H}_{2}}}{P_{\mathrm{CO}} \cdot P_{\mathrm{H}_{2} \mathrm{O}}}
\end{aligned}
$$

$A$ is the preexponential factor, $E_{a}$ is the apparent activation energy, $P_{i}$ is the partial pressure of component $i, P_{t}$ is the total pressure, $\beta$ is the approach to equilibrium, and $K_{g}$ is the equilibrium constant for the water-gas shift reaction. The activation energy, $\mathrm{E}_{\mathrm{a}}$, listed in the reference is $E_{a}=$ $86.5(\mathrm{~kJ} / \mathrm{mol})$. The experimental $\mathrm{E}_{\mathrm{a}}$ obtained by our study during this period is $E_{a}=114.2$ $(\mathrm{kJ} / \mathrm{mol})$. Details of the experimental results are listed in Table 1 and Figure 1 below. The preexponental factor, A, obtained based upon our experimental $\mathrm{E}_{\mathrm{a}}$ is $A=1.77 \times 10^{11}(\mathrm{~mol} / \mathrm{g}-\mathrm{hr}-$ $\left.\operatorname{bar}^{0.4}\right)$ 


\section{Table 1. Experimental Results for Kinetic Parameter Determination}

\begin{tabular}{|c|c|c|c|c|c|c|}
\hline Composition & \multicolumn{6}{|c|}{$\mathrm{CO}: \mathrm{H} 2: \mathrm{H} 2 \mathrm{O}=1.0: 4.0: 2.5$} \\
\hline Pressure(psig) & \multicolumn{2}{|c|}{52.5} & \multicolumn{2}{|c|}{50} & \multicolumn{2}{|c|}{50} \\
\hline Temperature $(\mathbf{C})$ & \multicolumn{2}{|c|}{205} & \multicolumn{2}{|c|}{225} & \multicolumn{2}{|c|}{250} \\
\hline Weight of Catalyst (g) & \multicolumn{2}{|c|}{10} & \multicolumn{2}{|c|}{30} & \multicolumn{2}{|c|}{30} \\
\hline \multirow{7}{*}{ Kinetic data } & $\begin{array}{l}\text { W/Fo CO } \\
(\mathrm{g} * \mathrm{hr} / \mathrm{mol}) \\
\end{array}$ & $\begin{array}{c}\mathrm{CO} \\
\text { Conversion }(\% \\
\end{array}$ & $\begin{array}{l}\text { W/Fo CO } \\
(\mathrm{g} * \mathrm{hr} / \mathrm{mol}) \\
\end{array}$ & $\begin{array}{c}\mathrm{CO} \\
\text { Conversion(\% } \\
\end{array}$ & $\begin{array}{l}\text { W/Fo CO } \\
(\mathrm{g} * \mathrm{hr} / \mathrm{mol}) \\
\end{array}$ & $\begin{array}{c}\text { CO } \\
\text { Conversion }(\%) \\
\end{array}$ \\
\hline & $1.56 \mathrm{E}+02$ & 77.96 & $4.67 \mathrm{E}+02$ & 96.52 & $4.67 \mathrm{E}+02$ & 96.63 \\
\hline & $7.78 \mathrm{E}+01$ & 68.47 & $2.33 \mathrm{E}+02$ & 95.23 & $2.33 \mathrm{E}+02$ & 95.21 \\
\hline & $5.19 \mathrm{E}+01$ & 61.66 & $1.56 \mathrm{E}+02$ & 92.22 & $1.56 \mathrm{E}+02$ & 92.94 \\
\hline & $3.89 \mathrm{E}+01$ & 50.93 & $1.17 \mathrm{E}+02$ & 88.19 & $1.17 \mathrm{E}+02$ & 88.43 \\
\hline & $3.11 \mathrm{E}+01$ & 47.96 & $9.33 \mathrm{E}+01$ & 79.38 & $9.33 \mathrm{E}+01$ & 86.35 \\
\hline & $2.59 \mathrm{E}+01$ & 38.48 & $7.78 \mathrm{E}+01$ & 71.78 & $7.78 \mathrm{E}+01$ & 77.86 \\
\hline Equilibrium Conversion of $\mathrm{CO}(\mathrm{d}$ & \multicolumn{2}{|c|}{98.30} & \multicolumn{2}{|c|}{97.54} & \multicolumn{2}{|c|}{96.27} \\
\hline
\end{tabular}

\begin{tabular}{|c|c|c|c|}
\hline$k=k 0 * \exp (-E / R$ & & & \\
\hline $\mathbf{T}(\mathbf{C})$ & 205 & 225 & 250 \\
\hline $\mathbf{T}(\mathbf{K})$ & 478.15 & 498.15 & 523.15 \\
\hline $\mathbf{R}\left(\mathrm{J} / \mathrm{mol}^{*} \mathrm{~K}\right)$ & 8.314 & 8.314 & 8.314 \\
\hline $\mathbf{k}$ & $5.39 \mathrm{E}-02$ & $2.21 \mathrm{E}-01$ & $6.46 \mathrm{E}-01$ \\
\hline $\ln (\mathbf{k})$ & $-2.92 \mathrm{E}+00$ & $-1.51 \mathrm{E}+00$ & $-4.37 \mathrm{E}-01$ \\
\hline 1/RT & $2.52 \mathrm{E}-04$ & $2.41 \mathrm{E}-04$ & $2.30 \mathrm{E}-04$ \\
\hline
\end{tabular}

\begin{tabular}{|c|c|}
\hline intercept $(=\ln (\mathbf{k o}))$ & 25.90 \\
\hline slope $(=-\mathbf{E})$ & -114218.6 \\
\hline
\end{tabular}

\begin{tabular}{|c|c|}
\hline $\begin{array}{c}\text { ko } \\
\text { g-mol/(g cat*hr*bar^0.4) }\end{array}$ & $1.77 \mathrm{E}+11$ \\
\hline $\begin{array}{c}\mathrm{E} \\
(\mathrm{J} / \mathrm{mol})\end{array}$ & 114218.6 \\
\hline $\begin{array}{c}\mathrm{E} \\
(\mathrm{KJ} / \mathrm{mol})\end{array}$ & 114.22 \\
\hline
\end{tabular}




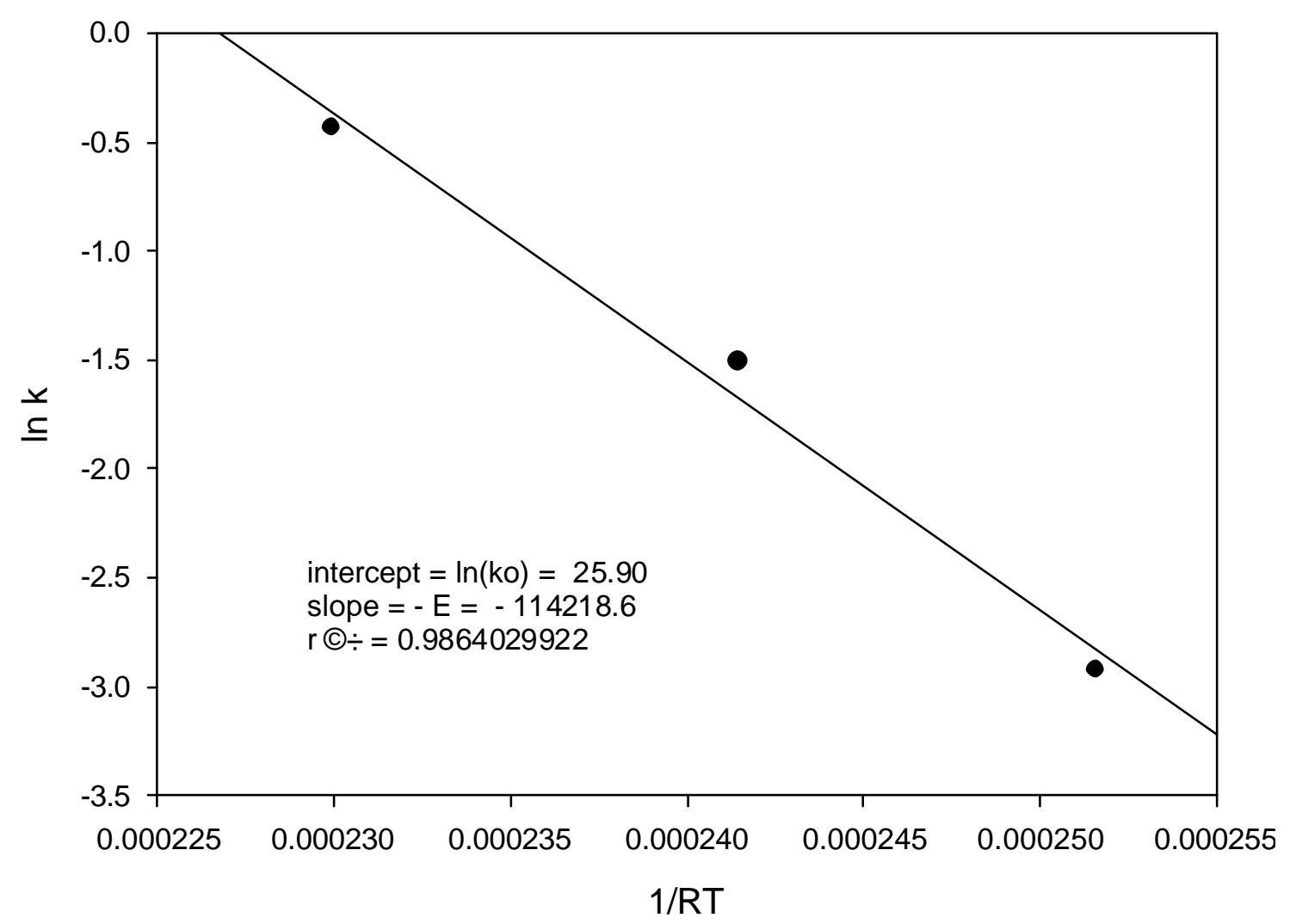

$\ln (k)$ vs. $1 / R T$

\section{Figure 1 Experimental determination of Ea and A based upon $\ln (\mathrm{k})$ vs. 1/RT}

The kinetic parameters, obtained for the Sud-Chemie catalyst used in this study, are different from that reported in the literature as shown above. As expected the MR performance predictions used ours vs the literature's are significantly different.

However, the performance trend and the comparative difference between the membrane reactor (MR) and the packed fixed-bed reactor (PFC) are quite similar as shown in Table 2. Throughout this study, we employed the kinetic parameters obtained from our experimental study. It is believed that the conclusions generated with our own kinetic parameters would be applicable to other cases. 
Table 2 Membrane Reactor Performance Prediction based upon Ours vs. Literature Kinetic Parameters

Case A. Using the kinetic parameters from the literature

$\mathrm{k}=1.52 \mathrm{E} 8$ (gmole/(gr catal.hr.bar^0.4)

$\mathrm{Ea}=86500(\mathrm{~J} / \mathrm{mol})$

\begin{tabular}{|c|c|c|c|c|c|c|c|}
\hline \multirow{2}{*}{ Xe } & \multicolumn{6}{|c|}{ W/FCO(g*hr/mol CO) required to reach 95\% of equilibrium conversion at PFR } \\
\cline { 2 - 8 } & \multirow{2}{*}{ PFR } & \multicolumn{2}{|c|}{ 1X H2 } & \multicolumn{2}{|c|}{ 5X H2 } & \multicolumn{2}{|c|}{ 10X H2 } \\
\hline & & MR-co & MR-counter & MR-co & MR-counter & MR-co & MR-counter \\
\hline 0.899 & 34.0 & 26.0 & 32.4 & 18.2 & 20.1 & 14.2 & 14.7 \\
\hline
\end{tabular}

\begin{tabular}{|c|c|c|c|c|c|c|c|}
\hline \multirow{2}{*}{ Xe } & \multicolumn{6}{|c|}{ W/FCO(g*hr/mol CO) required to reach 90\% of equilibrium conversion at PFR } \\
\cline { 2 - 8 } & \multirow{2}{*}{ PFR } & \multicolumn{2}{|c|}{ 1X H2 } & \multicolumn{2}{c|}{ 5X H2 } & \multicolumn{2}{|c|}{ 10X H2 } \\
\cline { 3 - 8 } & & MR-co & MR-counter & MR-co & MR-counter & MR-co & MR-counter \\
\hline 0.899 & 19.5 & 16.9 & 18.7 & 12.8 & 14.1 & 10.4 & 11.1 \\
\hline
\end{tabular}

Case B. Using the kinetic parameter we obtained experimentally

$\mathrm{k}=1.77 \mathrm{E} 11$ (gmole/(gr catal.hr.bar $\left.{ }^{\wedge} 0.4\right)$

$\mathrm{Ea}=114218.6(\mathrm{~J} / \mathrm{mol})$

\begin{tabular}{|c|c|c|c|c|c|c|c|}
\hline \multirow{3}{*}{$\mathrm{Xe}$} & \multicolumn{7}{|c|}{$\mathrm{D}\left(\mathrm{g}^{*} \mathrm{hr} / \mathrm{mol} \mathrm{CO}\right.$} \\
\hline & \multirow{2}{*}{ PFR } & \multicolumn{2}{|c|}{$1 \times H 2$} & \multicolumn{2}{|c|}{$5 \times \mathrm{H} 2$} & \multicolumn{2}{|c|}{$10 \times \mathrm{H} 2$} \\
\hline & & MR-co & MR-counter & MR-co & MR-counter & MR-co & MR-counter \\
\hline 0.899 & 23.6 & 17.5 & 19.9 & 13.0 & 14.2 & 1 & 10.7 \\
\hline
\end{tabular}

\begin{tabular}{|c|c|c|c|c|c|c|c|}
\hline \multirow{2}{*}{ Xe } & \multicolumn{6}{|c|}{ W/FCO(g*hr/mol CO) required to reach 90\% of equilibrium conversion at PFR } \\
\cline { 2 - 8 } & \multirow{2}{*}{ PFR } & \multicolumn{2}{|c|}{ 1X H2 } & \multicolumn{2}{c|}{ 5X H2 } & \multicolumn{2}{|c|}{ 10X H2 } \\
\cline { 3 - 8 } & & MR-co & MR-counter & MR-co & MR-counter & MR-co & MR-counter \\
\hline 0.899 & 12.9 & 11.2 & 11.8 & 9 & 9.7 & 7.5 & 7.9 \\
\hline
\end{tabular}

\subsection{Comparison of Packed Fixed-bed Reactor (PFR) vs Membrane Reactor (MR) for WGS-LTS (based upon simulation).}

The CO conversion (\%) vs W/F ranging from 10 to 60 was analyzed and is shown in Figure 2. In addition, three catalyst loading levels were chosen for our laboratory scale MR reactor, 10, 20 and $30 \mathrm{gm}$ as shown in the same figure. Table 1 lists the W/F required to reach a given level of conversion for PFR and MR including both counterand co-current operations. In addition, three different levels of hydrogen permeances were selected to display their effect on conversion. Key findings include:

- For the case using our own reaction kinetic parameters, the MR shows a $\sim 10$ to $40 \%$ reduction in reactor size over the PFR to reach $90 \%$ of the equilibrium conversion (89.9\%). A more dramatic reduction of 25 to $55 \%$ in the reactor size was realized at $95 \%$ of the equilibrium conversion. As is evident, as the conversion approaches the equilibrium conversion, the PFR becomes very inefficient in comparison with the MR.

- For the MR operation, the amount of the catalyst usage within the range of our study, i.e., 10 to $30 \mathrm{gm}$, shows very minor effect on the conversion level for a given $\mathrm{W} / \mathrm{F}$. 
- For MR, the performance of the co-current operation is similar to that of the counter-current operation. However, when the catalyst dosage or the flow rate is low (e.g., $\mathrm{W}=10 \mathrm{~g}$, or $\mathrm{Fco}=1 \mathrm{X}$ ) and the required conversion level is $\sim 80 \%$, the cocurrent operation requires less W/F than the counter-current operation. Although this may seem counter-intuitive, it appears, based upon the simulation results, that the loss of $\mathrm{CO}$ at the feed end of the reactor to the permeate is higher in the counter current case. Since this CO is now unavailable for reaction, the conversion is reduced.

- A CO concentration of 1,000 to $4,000 \mathrm{ppm}$ in the hydrogen product can be achieved in an MR. This contaminant level is much lower than that delivered by the PFR of 40,000 to >70,000 ppm. The much-reduced CO achieved with the MR results from the higher level of conversion and the in-situ product separation delivered by the membrane.

In summary, our mathematical simulation for the single stage LTS-WGS operation with MR demonstrates its unique advantage in achieving high $\mathrm{CO}$ conversion in a reactor volume that is 10 to $>55 \%$ less than the PFR requirement. In addition, the CO level is low at 1,000 to 4,000 ppm and can be readily post-treated with existing polishing technologies, such as PROX or methanation. In comparison, the PFR cannot deliver the $\mathrm{CO}$ contaminant at a level low enough for further treatment by the PROX or methanation; an additional unit operation to separate $\mathrm{CO}$ contaminant from hydrogen is necessary. 


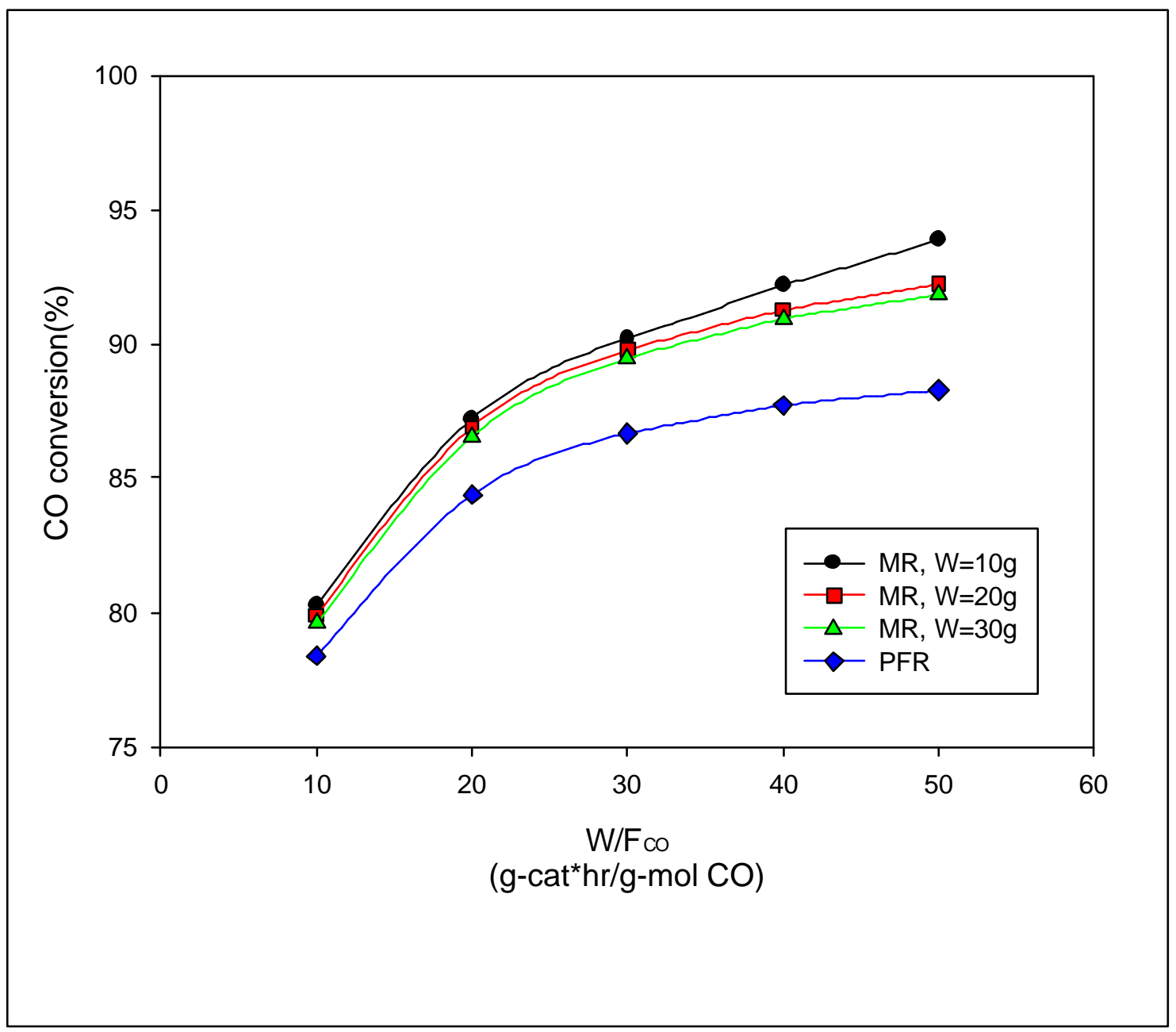

Figure 2 CO conversion (\%) with membrane reactor (MR) and packed fixed-bed reactor (PFR): varying the molar flow rate at the fixed $W$. 


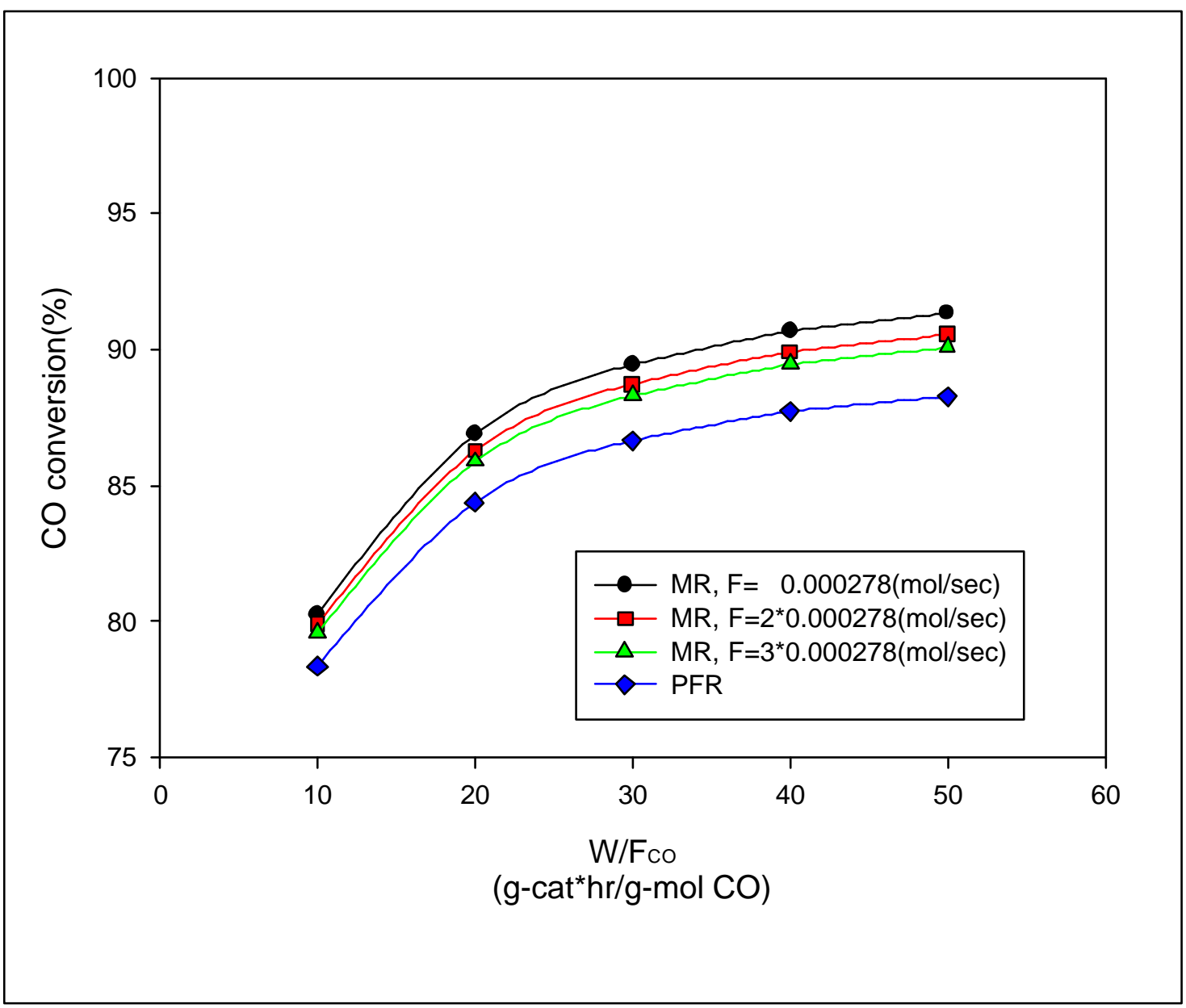

Figure 3 CO conversion vs W/F co for $M R$ and PFR: varying the amount of catalyst at the fixed $\mathbf{F}_{\text {co. }}$. 
Table 3 CO contaminant levels in the hydrogen products produced from PFR and MR with co- and count-current operation.

Coal gasifier-off gas compo s ition(Oxygen blown)

$\mathrm{T}=250$

$\mathrm{PF}=5 \mathrm{~atm}, \mathrm{PP}=1 \mathrm{~atm}$

Sweep gas ratio $=0.1$

$\mathrm{R}$ ich's case

\begin{tabular}{|c|c|c|c|c|c|c|c|c|}
\hline \multicolumn{10}{|c|}{ PF } & \multicolumn{3}{|c|}{ MR-co } & \multicolumn{3}{c|}{ MR-counter } \\
\hline \multirow{2}{*}{ W/F } & $\mathbf{X}$ & $\mathbf{C O}(\mathbf{p p m})$ & $\mathbf{X}$ & $\mathbf{C O}(\mathbf{p p m})$ & $\mathbf{R e}$ & $\mathbf{X}$ & $\mathbf{C O}(\mathbf{p p m})$ & $\mathbf{R e}$ \\
\hline $\mathbf{1 0}$ & 78.4 & 76777.0 & 80.3 & 3717.2 & 31.8 & 78.1 & 4007.8 & 31.9 \\
\hline $\mathbf{2 0}$ & 84.4 & 54271.0 & 87.2 & 3064.7 & 55.8 & 83.6 & 3687.8 & 56.8 \\
\hline $\mathbf{3 0}$ & 86.7 & 45999.0 & 90.2 & 2909.7 & 73.6 & 86.9 & 3936.9 & 75.1 \\
\hline $\mathbf{4 0}$ & 87.7 & 42156.0 & 92.2 & 2958.4 & 85.1 & 90.5 & 4483.9 & 86.4 \\
\hline $\mathbf{5 0}$ & 88.3 & 40195.0 & 93.9 & 3107.6 & 91.8 & 93.8 & 5271.1 & 92.2 \\
\hline
\end{tabular}

\begin{tabular}{|c|c|c|c|c|c|c|c|c|}
\hline \multicolumn{1}{|c|}{ MR-co } & \multicolumn{3}{c|}{ M ixed W=20 (g) } & \multicolumn{3}{c|}{ MR-counter } \\
\cline { 2 - 10 } W/F & $\mathbf{X}$ & $\mathbf{C O}(\mathbf{p p m})$ & $\mathbf{X}$ & $\mathbf{C O}(\mathbf{p p m})$ & $\mathbf{R e}$ & $\mathbf{X}$ & $\mathbf{C O}(\mathbf{p p m})$ & $\mathbf{R e}$ \\
\hline $\mathbf{1 0}$ & 78.4 & 76774.0 & 79.9 & 3337.2 & 17.5 & 78.9 & 3462.0 & 17.4 \\
\hline $\mathbf{2 0}$ & 84.4 & 54271.0 & 86.9 & 2567.1 & 32.2 & 85.0 & 2814.7 & 32.4 \\
\hline $\mathbf{3 0}$ & 86.7 & 45999.0 & 89.8 & 2243.8 & 45.2 & 87.5 & 2616.2 & 45.8 \\
\hline $\mathbf{4 0}$ & 87.7 & 42155.0 & 91.3 & 2085.7 & 56.6 & 89.0 & 2583.5 & 57.6 \\
\hline $\mathbf{5 0}$ & 88.3 & 40195.0 & 92.2 & 2015.4 & 66.3 & 90.5 & 2641.1 & 67.7 \\
\hline
\end{tabular}

\begin{tabular}{|c|c|c|c|c|c|c|c|c|}
\hline \multicolumn{19}{|c|}{ F ixed W=30 (g) } \\
\hline \multirow{2}{*}{ W/F } & \multicolumn{2}{|c|}{ PFR } & \multicolumn{3}{|c|}{ MR-co } & \multicolumn{3}{c|}{ MR-counter } \\
\cline { 2 - 11 }$y$ & $\mathbf{X}$ & $\mathbf{C O}(\mathbf{p p m})$ & $\mathbf{X}$ & $\mathbf{C O}(\mathbf{p p m})$ & $\mathbf{R e}$ & $\mathbf{X}$ & Co(ppm) & Re \\
\hline $\mathbf{1 0}$ & 78.4 & 76774.0 & 79.6 & 3196.5 & 12.2 & 79.0 & 3272.9 & 12.1 \\
\hline $\mathbf{2 0}$ & 84.4 & 54271.0 & 86.6 & 2411.9 & 22.8 & 85.3 & 2560.5 & 22.9 \\
\hline $\mathbf{3 0}$ & 86.7 & 45999.0 & 89.4 & 2067.5 & 32.5 & 87.8 & 2288.6 & 32.8 \\
\hline $\mathbf{4 0}$ & 87.7 & 42155.0 & 90.9 & 1878.4 & 41.4 & 89.2 & 2168.9 & 41.9 \\
\hline $\mathbf{5 0}$ & 88.3 & 40195.0 & 91.8 & 1768.2 & 49.6 & 90.2 & 2125.0 & 50.4 \\
\hline
\end{tabular}

\begin{tabular}{|c|c|c|c|c|c|c|c|c|}
\hline \multicolumn{9}{|c|}{ Fixed Fco=0.00027778 [mol/sec] } \\
\hline \multirow{2}{*}{ W/F } & \multicolumn{2}{|c|}{ PFR } & \multicolumn{3}{c|}{ MR-co } & \multicolumn{4}{c|}{ MR-counter } \\
\cline { 2 - 10 }$y$ & $\mathbf{X}$ & $\mathbf{C O}(\mathbf{p p m})$ & $\mathbf{X}$ & $\mathbf{C O}(\mathbf{p p m})$ & $\mathbf{R e}$ & $\mathbf{X}$ & $\mathbf{C O}(\mathbf{p p m})$ & $\mathbf{R e}$ \\
\hline $\mathbf{1 0}$ & 78.4 & 76774.0 & 80.3 & 3717.2 & 31.8 & 78.1 & 4007.8 & 31.9 \\
\hline $\mathbf{2 0}$ & 84.4 & 54271.0 & 86.9 & 2567.1 & 32.2 & 85.0 & 2814.7 & 32.4 \\
\hline $\mathbf{3 0}$ & 86.7 & 45999.0 & 89.4 & 2067.5 & 32.5 & 87.8 & 2288.6 & 32.8 \\
\hline $\mathbf{4 0}$ & 87.7 & 42155.0 & 90.7 & 1784.2 & 32.7 & 89.3 & 1986.0 & 33.0 \\
\hline $\mathbf{5 0}$ & 88.3 & 40195.0 & 91.3 & 1602.0 & 32.9 & 90.2 & 1788.8 & 33.2 \\
\hline
\end{tabular}

\begin{tabular}{|c|c|c|c|c|c|c|c|c|}
\hline \multicolumn{9}{|c|}{ Fixed Fco=2 X 0.00027778 [mol/sec] } \\
\hline \multirow{2}{*}{ W/F } & \multicolumn{2}{|c|}{ PFR } & \multicolumn{3}{|c|}{ MR-co } & \multicolumn{3}{c|}{ MR-counter } \\
\cline { 2 - 10 } & $\mathbf{X}$ & $\mathbf{C O}(\mathbf{p p m})$ & $\mathbf{X}$ & $\mathbf{C O}(\mathbf{p p m})$ & $\mathbf{R e}$ & $\mathbf{X}$ & $\mathbf{C O}(\mathbf{p p m})$ & $\mathbf{R e}$ \\
\hline $\mathbf{1 0}$ & 78.4 & 76774.0 & 79.9 & 3337.2 & 17.5 & 78.9 & 3462.0 & 17.4 \\
\hline $\mathbf{2 0}$ & 84.4 & 54271.0 & 86.3 & 2330.5 & 17.8 & 85.4 & 2433.7 & 17.8 \\
\hline $\mathbf{3 0}$ & 86.7 & 45999.0 & 88.7 & 1891.9 & 18.0 & 88.0 & 1983.2 & 18.0 \\
\hline $\mathbf{4 0}$ & 87.7 & 42155.0 & 89.9 & 1642.3 & 18.1 & 89.2 & 1725.5 & 18.1 \\
\hline $\mathbf{5 0}$ & 88.3 & 40195.0 & 90.5 & 40195.0 & 18.2 & 90.0 & 1558.4 & 18.3 \\
\hline
\end{tabular}

\begin{tabular}{|c|c|c|c|c|c|c|c|c|}
\hline \multicolumn{9}{|c|}{ Fixed FCO $=3 \times 0.00027778[\mathrm{~mol} / \mathrm{sec}]$} \\
\hline \multirow[b]{2}{*}{ W/F } & \multicolumn{2}{|c|}{ PFR } & \multicolumn{3}{|c|}{ MR-co } & \multicolumn{3}{|c|}{ MR-counter } \\
\hline & $x$ & CO(ppm) & $x$ & co(ppm) & $\mathbf{R e}$ & $x$ & $\mathrm{CO}(\mathrm{ppm})$ & $\operatorname{Re}$ \\
\hline 10 & 78.4 & 76774.0 & 79.6 & 3196.5 & 12.2 & 79.0 & 3272.9 & 12.1 \\
\hline
\end{tabular}




\subsection{Experimental Verification of Mathematical Model}

- $\mathrm{CO}$ conversions vs $\mathrm{W} / \mathrm{F}$ at $250^{\circ} \mathrm{C}$ for the feed specified above are presented in Figure 4. Also shown in the figure is the $\mathrm{CO}$ conversion based upon the thermodynamic calculation. Permeances for each component were experimentally determined: 1.12, $0.066,0.163,1.55 \mathrm{~m}^{3} / \mathrm{m}^{2} / \mathrm{hr} / \mathrm{bar}$ for $\mathrm{H}_{2}, \mathrm{CO}, \mathrm{CO}_{2}$ and $\mathrm{H}_{2} \mathrm{O}$ respectively. With these physical and rate parameters, the $\mathrm{CO}$ conversion vs $\mathrm{W} / \mathrm{F}$ predicted by the mathematical model developed in this study is presented in Figure 4. The MR shows about $10 \%$ enhancement over the PFR at this operating condition.

- About 90 and $91 \%$ conversion were obtained at $\mathrm{W} / \mathrm{F}=350$ and 400 respectively. These experimental results correlate well with the prediction shown in Figure 4. Additional experimental data will be generated by the end of Year II, particularly in the range of $\mathrm{W} / \mathrm{F}=50$ to 200 , where the $\mathrm{CO}$ conversion is more sensitive to the change of W/F.

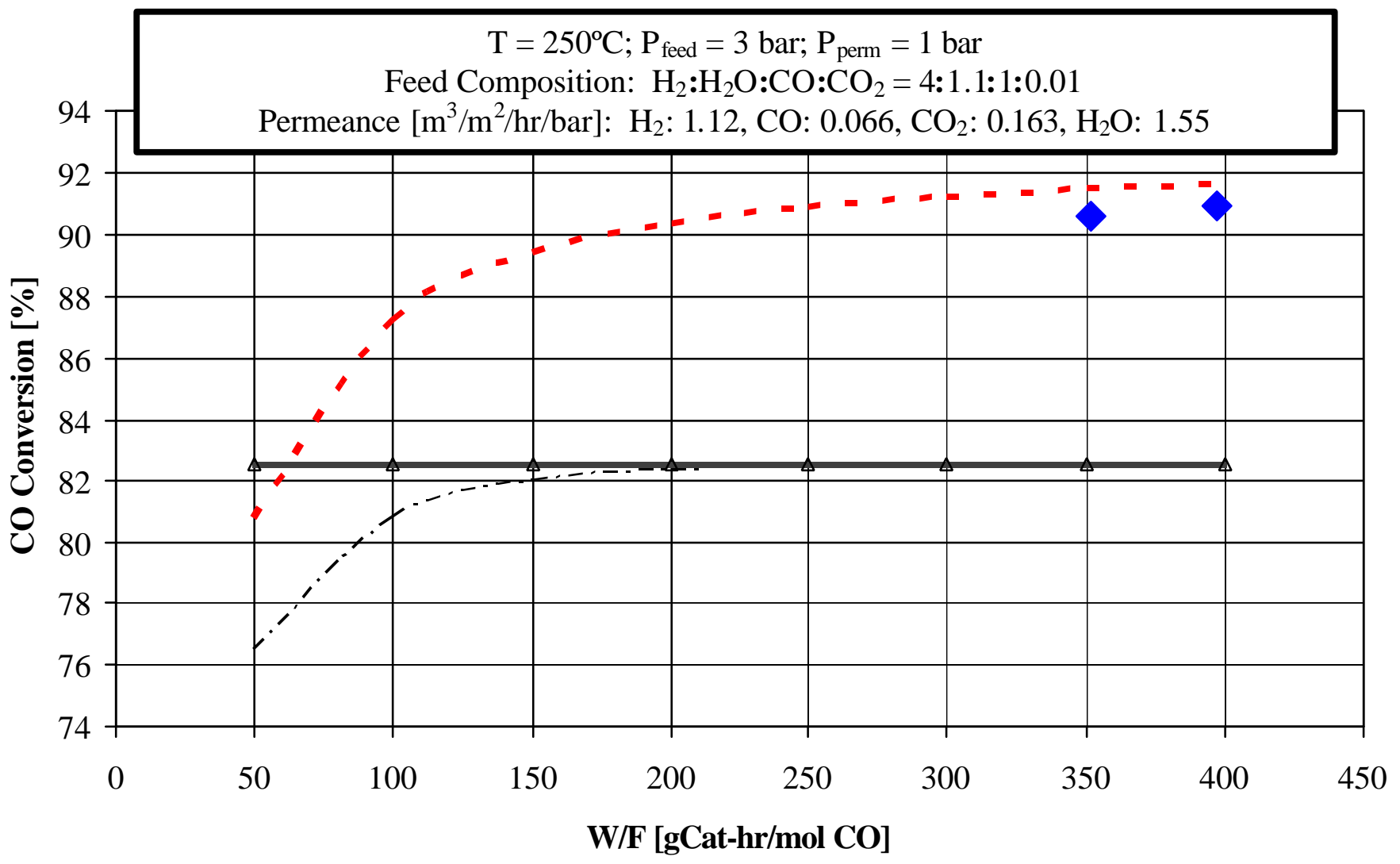
- - - Membrane Reactor: Simulation - - - - Plug Flow Reactor: Simulation
$\triangle$ Equilibrium Conversion $\leadsto$ MR Experimental Results

Figure 4 LTS-WGS USING OUR CMS MEMBRANES AS MR: Experimental vs Simulation Results 


\subsection{Temperature Rise and Thermal Management of Proposed Single Stage LTS.}

The exothermic WGS reaction could cause the reactor temperature to rise significantly. To protect the catalyst, an effective thermal management is essential. In the past, the WGS reaction was primarily implemented in the steam reformed stream containing 7 to $10 \% \mathrm{CO}$. Thus the temperature rise is not as severe as the WGS for the coal gasifier offgas, which contains $>30 \% \mathrm{CO}$. To accomplish the process intensification objective, instead of using the conventional multiple inter-stage cooler, we have developed an elegant solution to integrate the thermal management into the membrane reactor. An innovative membrane was also developed to accomplish this objective. Due to the proprietary nature of this innovative thermal management approach, no detailed discussion is made here.

\subsection{Full Scale Membrane and Module Production}

Quantities Produced and On-Spec Ratio... A total of 98 membrane tubes have been produced thus far. We set our spec at a $\mathrm{H}_{2}$ permeance of $>0.35 \mathrm{~m}^{3} / \mathrm{m}^{2} / \mathrm{hr}$ and $\mathrm{H}_{2} / \mathrm{N}_{2}$ selectivity of $>50$ selectivity at $120^{\circ} \mathrm{C}$. This would translate into a $\mathrm{H}_{2}$ permeance of $>0.5$ $\mathrm{m}^{3} / \mathrm{m}^{2} / \mathrm{hr} /$ bar and $\mathrm{H}_{2} / \mathrm{N}_{2}$ selectivity of $>75$ at the target operating temperature of $250^{\circ} \mathrm{C}$. About 23 out of 98 tubes failed to meet this spec during the first production trial., which leads to $>75 \%$ on-spec ratio. Please refer to Figure 5 and Table 3 for details.

Full-Scale Module Fabrication... One of the major challenges for ceramic based membranes is its scale up potential. During this reporting period, we have come out with a flexible design, which allows us to fabricate membrane modules with $>30 \mathrm{~m}^{2} /$ module without using exotic engineering or materials. This would qualify the ceramic membrane and module for mega-scale applications, such as the proposed application, which usually requires several hundred square meters. With the availability of our innovative module design, ceramic membranes no longer suffer this scale-up disadvantage. Due to the proprietary nature of the design, no details are disclosed here. 
Table 4 Characterization of Full-scale Hydrogen Selective Membrane (30''L) produced during this period

\begin{tabular}{|c|c|c|c|c|c|c|}
\hline \multirow{2}{*}{ Tube \# } & \multirow{2}{*}{$\begin{array}{c}\text { Temp } \\
{[\mathrm{C}]}\end{array}$} & \multicolumn{2}{|c|}{ Permeance [m3/m2/hr/bar] } & \multicolumn{2}{|l|}{ Selectivity } & \multirow{2}{*}{ Fail to meet Spec.* } \\
\hline & & $\mathrm{He}$ & $\mathrm{H} 2$ & $\mathrm{He} / \mathrm{N} 2$ & $\mathrm{H} 2 / \mathrm{N} 2$ & \\
\hline 113 & 120 & 0.188 & 0.524 & 19 & 53 & \\
\hline 114 & 120 & 0.306 & 0.765 & 32 & 80 & \\
\hline 128 & 120 & 0.753 & 1.390 & 39 & 72 & \\
\hline 129 & 120 & 0.382 & 0.974 & 20 & 51 & \\
\hline 130 & 120 & 0.278 & 0.649 & 42 & 98 & \\
\hline 132 & 120 & 0.523 & 1.068 & 47 & 96 & \\
\hline 135 & 120 & 0.899 & 2.055 & 35 & 80 & \\
\hline 137 & 120 & 0.454 & 0.856 & 87 & 164 & \\
\hline 140 & 120 & 0.303 & 0.598 & 73 & 144 & \\
\hline 141 & 120 & 0.279 & 0.728 & 59 & 154 & \\
\hline 143 & 120 & 0.557 & 1.346 & 24 & 58 & \\
\hline 145 & 120 & 0.293 & 0.760 & 27 & 70 & \\
\hline 147 & 120 & 0.271 & 0.690 & 33 & 84 & \\
\hline 148 & 120 & 0.548 & 1.370 & 34 & 85 & \\
\hline 153 & 120 & 0.319 & 0.775 & 28 & 68 & \\
\hline 156 & 120 & 0.220 & 0.436 & 88 & 175 & \\
\hline 163 & 120 & 0.244 & 0.397 & 56 & 91 & \\
\hline 164 & 120 & 0.204 & 0.345 & 28 & 47 & $\mathrm{x}$ \\
\hline 168 & 120 & 0.132 & 0.157 & 43 & 51 & $\mathrm{x}$ \\
\hline 169 & 120 & 0.177 & 0.253 & 150 & 214 & $\mathrm{x}$ \\
\hline 171 & 120 & 0.118 & 0.146 & 38 & 47 & 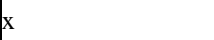 \\
\hline 175 & 120 & 0.225 & 0.500 & 68 & 152 & \\
\hline 177 & 120 & 0.278 & 0.666 & 31 & 73 & \\
\hline 178 & 120 & 0.259 & 0.604 & 21 & 49 & $\mathrm{x}$ \\
\hline 180 & 120 & 0.684 & 1.683 & 28 & 70 & \\
\hline 182 & 120 & 0.413 & 0.897 & 19 & 40 & \\
\hline 183 & 120 & 0.203 & 0.371 & 178 & 324 & \\
\hline 184 & 120 & 0.306 & 0.638 & 73 & 151 & \\
\hline 185 & 120 & 0.246 & 0.604 & 30 & 74 & \\
\hline 187 & 120 & 0.142 & 0.266 & 25 & 46 & $\mathrm{x}$ \\
\hline 188 & 120 & 0.544 & 1.265 & 28 & 64 & \\
\hline 190 & 120 & 0.399 & 0.977 & 44 & 109 & \\
\hline 196 & 120 & 0.370 & 0.763 & 79 & 163 & \\
\hline 197 & 120 & 0.204 & 0.353 & 237 & 409 & \\
\hline 198 & 120 & 0.679 & 1.531 & 25 & 56 & \\
\hline 200 & 120 & 0.678 & 1.356 & 30 & 60 & \\
\hline 201 & 120 & 0.147 & 0.254 & 307 & 532 & $\mathrm{x}$ \\
\hline 202 & 120 & 0.699 & 1.625 & 18 & 42 & $\mathrm{x}$ \\
\hline 203 & 120 & 0.318 & 0.641 & 112 & 225 & \\
\hline 204 & 120 & 0.170 & 0.308 & 119 & 215 & $\mathrm{x}$ \\
\hline 205 & 120 & 0.323 & 0.690 & 30 & 64 & \\
\hline 206 & 120 & 0.416 & 0.707 & 59 & 100 & \\
\hline 207 & 120 & 0.425 & 0.773 & 54 & 99 & \\
\hline 208 & 120 & 0.241 & 0.444 & 31 & 58 & \\
\hline 210 & 120 & 0.310 & 0.637 & 91 & 187 & \\
\hline 211 & 120 & 0.302 & 0.659 & 73 & 160 & \\
\hline 214 & 120 & 0.297 & 0.523 & 214 & 377 & \\
\hline 215 & 120 & 0.232 & 0.355 & 75 & 114 & \\
\hline 216 & 120 & 0.239 & 0.349 & 122 & 178 & \\
\hline 218 & 120 & 0.253 & 0.389 & 150 & 230 & \\
\hline 219 & 120 & 0.234 & 0.347 & 41 & 61 & \\
\hline 220 & 120 & 0.203 & 0.285 & 155 & 217 & $\mathrm{x}$ \\
\hline 221 & 120 & 0.236 & 0.359 & 57 & 86 & \\
\hline 223 & 120 & 0.246 & 0.480 & 24 & 46 & \\
\hline 226 & 120 & 0.151 & 0.282 & 43 & 80 & $\mathrm{x}$ \\
\hline 227 & 120 & 0.200 & 0.320 & 178 & 285 & $\mathrm{x}$ \\
\hline 228 & 120 & 0.367 & 0.697 & 26 & 50 & \\
\hline 229 & 120 & 0.218 & 0.321 & 125 & 183 & \\
\hline
\end{tabular}




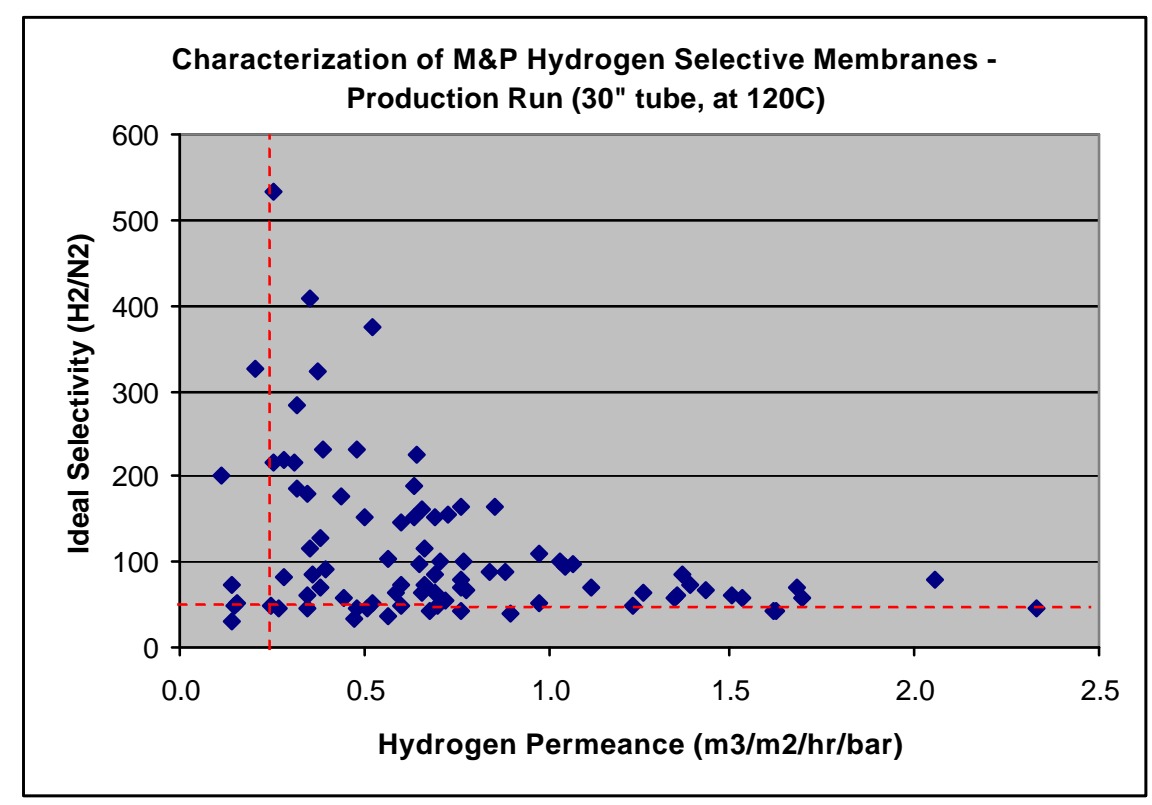

Figure 5. $\mathrm{H}_{2}$ permeance vs. selectivity of full scale membrane tubes prepared during this period.

\subsection{Simulation of WGS Under Field Operating Condition}

Conversion under Adequate Permeate Sweep...88 - 98\% CO conversion can be achieved with the MR in comparison with $82-89 \%$ by the conventional packed bed using a sweep rate of 10 to $40 \%$ (sweep ratio of 0.1 to 0.4 ) of the feed. The conversion vs W/F with the sweep ratio as a parameter is presented in Figure 6. The sweep ratio of 0.3 appears sufficient.

MR vs PFR under Field Operating Condition...96\% CO conversion and <2,000 ppm CO can be produced with the proposed MR vs $\sim 88 \%$ conversion and 60,000 ppm CO for the packed bed. The advantage of the membrane performance was enhanced as a result of the increase in the feed pressure and the hydrogen permeance and selectivity used here. The significant improvement in CO conversion and, more importantly, about 30 times reduction in $\mathrm{CO}$ contaminant level reinforce the advantage of the membrane reactor for WGS under a field operating condition with our state-of-the-art membrane. Optimization will begin once the experimental verification is completed by the end of Yr II.

Simulation of Test Unit at PFDU...Presently, this mathematical model has been utilized to simulate the WGS operation at PFDU (Wilsonville, AL). Several operating conditions have been provided by PFDU engineers for us to simulate the hydrogen separation potential. Our simulation results were then used to estimate its potential improvement in WGS by PFDU personnel using its ASPEN model. The potential improvement of using 
our membranes and membrane reactors will be documented in the $2^{\text {nd }}$ semiannual report of Yr II. A field test is planned in Yr III using the membrane module provided by Media and Process Technology Inc.

Membrane Performance Stability in Presence of Concentrated $\mathrm{H}_{2} \mathrm{~S}$...The field test results generated at the refinery pilot test facility are summarized in Figure 7 . At $220^{\circ} \mathrm{C}$ and 10 bar, a stable hydrogen permeance of $1.1 \mathrm{~m}^{3} / \mathrm{m}^{2} / \mathrm{hr} /$ bar was obtained throughout the test period of about $120 \mathrm{hrs}$. Hydrogen purity was enriched from $\sim 90 \%$ to $99.9 \%$ with the hydrogen recovery ratio of 85 to $92 \%$. In addition, the $\mathrm{H}_{2} \mathrm{~S}$ concentration was reduced from $5.2 \%$ in the feed to $=0.16 \%$ in the permeate. More importantly, no membrane permeance degradation was observed under this concentrated $\mathrm{H}_{2} \mathrm{~S}$ environment.

Membrane Regeneration after Challenge Test...The aggressive "dead-head" (no reject flow) challenge test reduced the permeance substantially; however, our regeneration restored the original permeance as presented in Table 4. Hydrogen permeance of 1.27 $\mathrm{m}^{3} / \mathrm{m}^{2} / \mathrm{hr} /$ bar and the selectivity of $\sim 75$ for hydrogen over nitrogen at $220^{\circ} \mathrm{C}$ were obtained before the challenge test. The dead head challenge test was conducted for 17 hours so that the contaminant levels far exceeded those in the standard run, including $>>30 \% \mathrm{H}_{2} \mathrm{~S}$ and heavy hydrocarbons. As a result, the membrane was poisoned and its permeance was reduced by $\sim 50 \%$ to $0.62 \mathrm{~m}^{3} / \mathrm{m}^{2} / \mathrm{hr} / \mathrm{bar}$. However, this permeance loss was restored via our proprietary regeneration technique to nearly the original level, i.e., $1.26 \mathrm{~m}^{3} / \mathrm{m}^{2} / \mathrm{hr} / \mathrm{bar}$ and the selectivity of 67 . Based upon the results from the poison study in the field and its regeneration, we believe that our CMS membrane can be regenerated in case the membrane is accidentally poisoned.
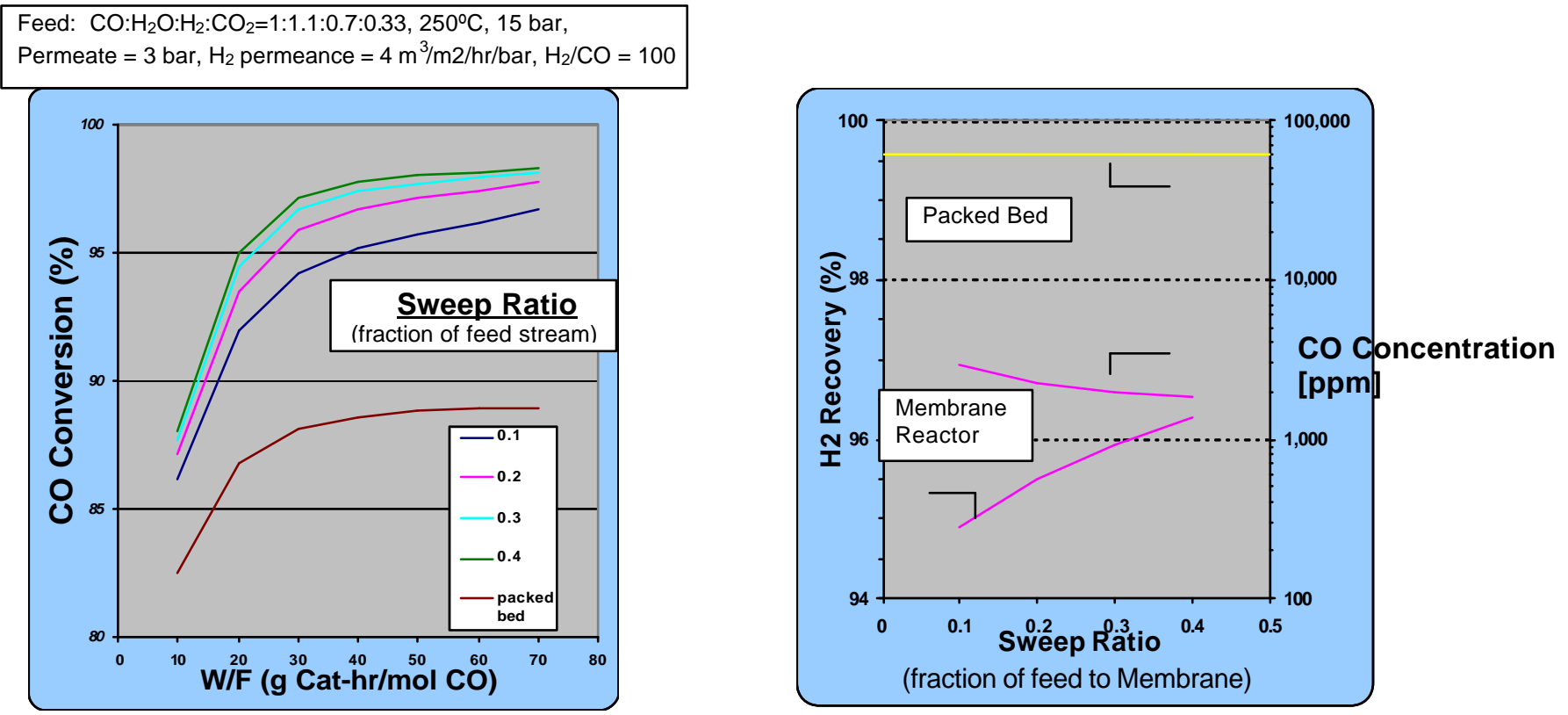

Figure 6. Effect of permeate sweep gas rate on $\mathrm{CO}$ conversion with our proposed membrane reactor 


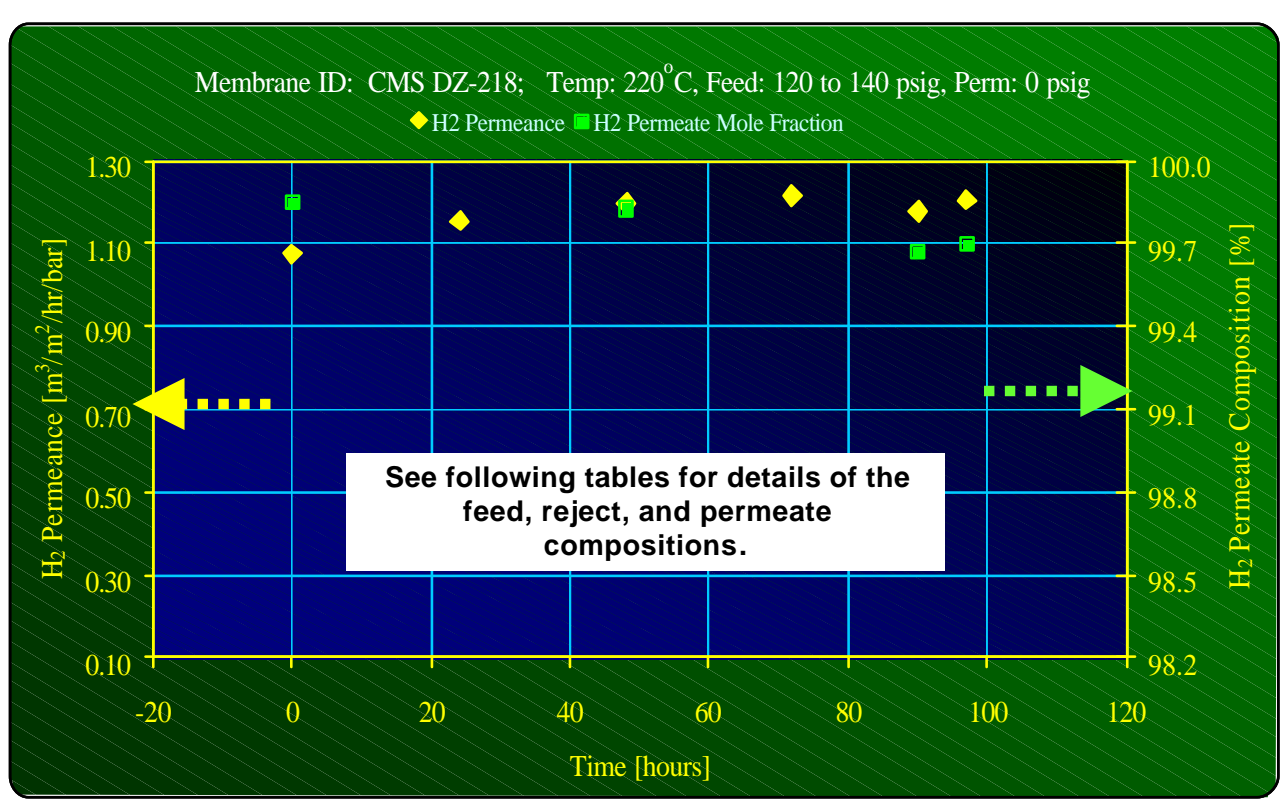

During this $100 \mathrm{hr}$ field test, our membrane shows excellent $\mathrm{H}_{2}$ permeance and selectivity in the presence of $\mathrm{H}_{2} \mathrm{~S}$, ammonia and hydrocarbons.

\begin{tabular}{|c|c|c|c|c||}
\hline \multicolumn{5}{|c|}{ At time = 3 hours } \\
\hline \multirow{2}{*}{ Gas } & \multicolumn{3}{|c|}{ Composition [\%] } & $\begin{array}{c}\text { H}_{2} / \text { Slow } \\
\text { Selectivity }\end{array}$ \\
\cline { 2 - 5 } & Feed & Reject & Permeate & 163 \\
\hline $\mathrm{H}_{2} \mathrm{~S}$ & 5.2 & 32.0 & 0.03 & 1 \\
\hline $\mathrm{H}_{2}$ & 89.9 & 38.9 & 99.88 & 123 \\
\hline $\mathrm{C}_{1}$ & 2.1 & 12.2 & 0.08 & $\sim 600$ \\
\hline $\mathrm{C}_{2}$ & 0.88 & 5.4 & 0.01 & $>1,000$ \\
\hline $\mathrm{C}_{3}+$ & 1.88 & 11.6 & $\mathrm{ND}$ & $\mathbf{8 5 \%}$ \\
\hline \multicolumn{6}{|c|}{ Stage Cut } & \multicolumn{2}{|c|}{$\mathbf{9 2 \%}$} \\
\hline \multicolumn{6}{|c|}{ H $_{2}$ Recovery } & \multicolumn{2}{|c|}{} \\
\hline
\end{tabular}

\begin{tabular}{|c|c|c|c|c|}
\hline \multicolumn{5}{|c|}{ At time = 100 hours } \\
\hline \multirow{2}{*}{ Gas } & \multicolumn{3}{|c|}{ Composition [\%] } & $\begin{array}{c}\text { H}_{2} / \text { Slow } \\
\text { Selectivity }\end{array}$ \\
\cline { 2 - 4 } & Feed & Reject & Permeate & 74 \\
\hline $\mathrm{H}_{2} \mathrm{~S}$ & 4.8 & 24.5 & 0.16 & 1 \\
\hline $\mathrm{H}_{2}$ & 90.8 & 50.6 & 99.70 & 123 \\
\hline $\mathrm{C}_{1}$ & 1.9 & 9.9 & 0.06 & $\sim 600$ \\
\hline $\mathrm{C}_{2}$ & 0.81 & 4.2 & 0.01 & $>1,000$ \\
\hline $\mathrm{C}_{3}+$ & 1.66 & 10.7 & $\mathrm{ND}$ & $\mathbf{8 0 \%}$ \\
\hline \multicolumn{6}{|c|}{ Stage Cut } & \multicolumn{2}{c|}{$\mathbf{8 5 \%}$} \\
\hline \multicolumn{6}{|c|}{ H $_{2}$ Recovery } & \multicolumn{2}{c|}{} \\
\hline
\end{tabular}

Figure 7 Gas Stream Compositions and Stage Cut and $\mathrm{H}_{2}$ Recovery for the VGO Hydrocracker Pilot Test 
Table 5 Degradation of the carbon molecular sieve membrane challenged by the dead-end operation and the restoration of the original permeance via regeneration.

\section{Membrane Regeneration}

Pure Component Permeance and Selectivity

Test Conditions: $220^{\circ} \mathrm{C} @ \sim 120$ psig

Test Phase
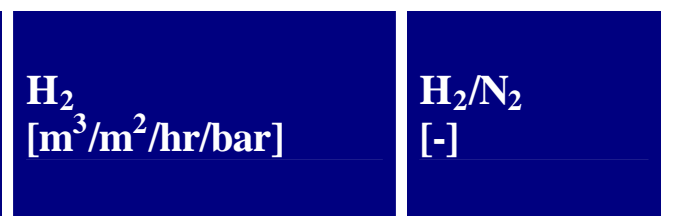

\section{Before Hydrocracker Testing}

\subsection{7}

75

\section{After Hydrocracker Testing}

After Dead Head Hydrocracker Challenge
Test
Stage Cut)
>> Permeate flow falls from $\sim 450$ to $\sim 3$
cc/min

After Regeneration
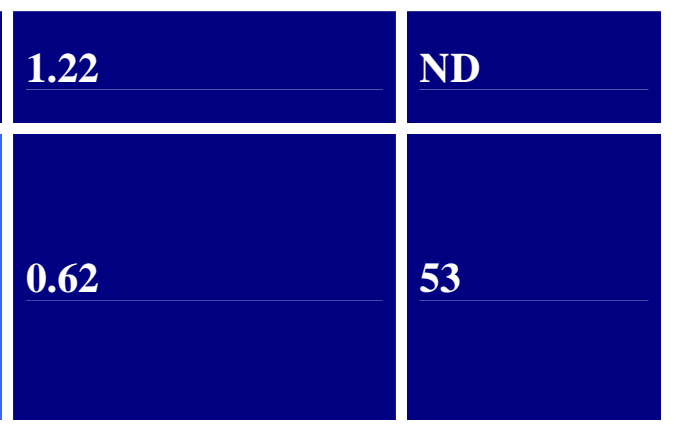


\section{Appendix I Mathematical Model for Proposed Membrane Reactor for Water-Gas-Shift Reacti}

$$
\begin{gathered}
\mathrm{CO}+\mathrm{H}_{2} \mathrm{O} \Leftrightarrow \mathrm{CO}_{2}+\mathrm{H}_{2} \\
r=k \frac{P_{\mathrm{CO}} P_{\mathrm{H}_{2} \mathrm{O}}^{1.4}}{P_{\mathrm{H}_{2}}^{0.9} P_{\mathrm{CO}_{2}}^{0.7}}(1-\beta) \frac{1}{P_{t}^{0.4}} \\
\beta=\frac{P_{\mathrm{CO}_{2}} P_{\mathrm{H}_{2}}}{K_{e} P_{\mathrm{H}_{2}} \mathrm{P}_{\mathrm{CO}}} \\
k=k_{o} \cdot \exp \left(-\frac{E_{a}}{R T}\right)
\end{gathered}
$$

$k_{o}$ is the preexponential factor, $E_{a}$ is the apparent activation energy, $P_{j}$ is the partial pressure of component $j, P_{t}$ is the total pressure, $\beta$ is the approach to equilibrium and $K_{g}$ is the equilibrium constant for the water-gas shift reaction.

Mass transfer through the porous membrane is described by the following empirical equation:

$$
F_{j}=U_{j}\left(P_{j}^{F}-P_{j}^{P}\right)
$$

where $F_{j}$ is the molar flux $\left(\mathrm{mol} / \mathrm{m}^{2} \cdot \mathrm{s}\right), P_{j}^{F}$ the partial pressure of component $j$ on the membrane feed side (bar), $P_{j}^{P}$ the partial pressure of component $j$ on the membrane permeate side (bar), and $U_{j}$ the membrane permeance for component $j\left(\mathrm{~mol} / \mathrm{m}^{2} \cdot \mathrm{bar} \cdot \mathrm{s}\right)$.

The mass balance on the feed side of the reactor packed with water gas shift reaction catalyst is described by the following equations for $\mathrm{CO}_{2}, \mathrm{CO}, \mathrm{H}_{2}, \mathrm{H}_{2} \mathrm{O}$ and an inert species (potentially used as a sweep gas or a blanketing agent; for catalytic water gas shift reaction, a practical sweep gas would be either steam or hydrogen, however):

Feed side: $\quad \frac{\partial n_{j}^{F}}{\partial z}=-\alpha_{m} U_{j}\left(P_{j}^{F}-P_{j}^{P}\right)+v_{j} A_{c} r^{F}$

Permeate side: $\frac{\partial n_{j}^{P}}{\partial z}=\alpha_{m} U_{j}\left(P_{j}^{F}-P_{j}^{P}\right)$

$$
\begin{aligned}
& j=1,2 \ldots . \mathrm{n} \\
& \text { at } z=0, \quad n_{j}=n_{j o}
\end{aligned}
$$

In eq. 6 and $7, n_{j}^{F}$ is the molar flow rate (mol/s) for species $j$ on the feed side. $n_{j}^{P}$ is the molar flow rate $(\mathrm{mol} / \mathrm{s})$ for species $j$ on the permeate side, $z$ is the reactor length variable $(\mathrm{m}), A_{c}$ the cross-sectional area available to flow for the reactor feed side $\left(\mathrm{m}^{2}\right), \alpha_{m}$ the 
inner circumference of the membrane $(\mathrm{m}), v_{i}$ the stoichiometric coefficient of component $j$ and $r^{F}$ the reaction rate expression.

The pressure drop in a packed bed can be calculated using the Ergun equation:

$$
\begin{gathered}
-\frac{d P^{F}}{d z}=10^{-6} \frac{f\left(G^{F}\right)^{2}}{g_{c} d_{P} \rho^{F}} \\
\text { at } z=0, \quad P^{F}=P_{0}^{F} \\
f=\left(\frac{1-\varepsilon_{v}}{\left(\varepsilon_{v}\right)^{3}}\right)\left(1.75+\frac{150\left(1-\varepsilon_{v}\right)}{N_{\mathrm{Re}}^{F}}\right) \\
N_{\mathrm{Re}}^{F}<500\left(1-\varepsilon_{v}\right) \\
N_{\mathrm{Re}}^{F} \equiv d_{P} G^{F} / \mu^{F}
\end{gathered}
$$

where $P^{F}$ is the feed-side pressure (bar), $P_{0}^{F}$ the inlet feed-side pressure, $\mu^{F}$ the viscosity (Pa.s), $d_{P}$ the particle diameter in the feed side (m), $G^{F}=\rho^{F} u^{F}$ the superficial mass flow velocity in the feed side $\left(\mathrm{kg} / \mathrm{m}^{2} \cdot \mathrm{s}\right), u^{F}$ the average velocity of the fluid, $\rho^{F}$ the average density of the fluid $\left(\mathrm{kg} / \mathrm{m}^{3}\right)$, and $g_{c}$ the gravity conversion factor equal to 1 in SI units.

The reactor conversion (based on $\mathrm{CO}$, which is typically the limiting reagent) is defined by the following equation:

$$
X_{C O}=\frac{n_{C O_{0}}^{F}-\left(n_{C O_{e x}}^{F}+n_{C O_{e x}}^{P}\right)}{n_{C O_{0}}^{F}}
$$

where $n_{C O_{0}}^{F}$ is the inlet molar flow rate of $\mathrm{CO}$ and $n_{C O_{e x}}^{F}$ and $n_{C O_{e x}}^{P}$ are the CO molar flow rates at the exit of the reactor feed and permeate sides correspondingly $(\mathrm{mol} / \mathrm{s})$. The yield of product hydrogen, defined as the fraction of moles of $\mathrm{CO}$ fed into the reactor that have reacted to produce hydrogen, is given by the following equation:

$$
Y_{H_{2}}=\frac{\left(n_{H_{2, e x}}^{F}-n_{H_{2,0}}^{F}\right)+\left(n_{H_{2, e x}}^{P}-n_{H_{2,0}}^{P}\right)}{n_{C O_{0}}^{F}}
$$

where $n_{H_{2 e x}}^{F}$ and $n_{H_{2 e x}}^{P}$ are the hydrogen molar flow rates at the exit of respectively the reactor feed and permeate sides and $n_{H_{2,0}}^{F}$ and $n_{H_{2,0}}^{P}$ the $\mathrm{H}_{2}$ molar flow rates potentially present at the inlet of the reactor feed and permeate sides $(\mathrm{mol} / \mathrm{s}) . Y_{\mathrm{H} 2}=1$ when all of the $\mathrm{CO}$ has reacted completely to produce $\mathrm{CO}_{2}$ and $\mathrm{H}_{2}$. 
Equations $1.7-1.10$ can be written by defining the following variables and groups:

$$
\begin{aligned}
& n_{o}^{F}=\sum_{j} n_{j o}^{F} ; n_{o}^{P}=\sum_{j} n_{j o}^{P} ; n^{F}=n_{o}^{F} \sum_{j} x_{j}^{F} ; n^{P}=n_{o}^{P} \sum_{j} x_{j}^{P} \\
& x_{j}^{F} \equiv \frac{n_{j}^{F}}{n_{o}^{F}} ; x_{j}^{P} \equiv \frac{n_{j}^{P}}{n_{o}^{P}} \\
& y_{j}^{F}=\frac{n_{j}^{F}}{n^{F}}=\frac{x_{j}^{F}}{\sum_{j} x_{j}^{F}} ; y_{j}^{P}=\frac{n_{j}^{P}}{n^{P}}=\frac{x_{j}^{P}}{\sum_{j} x_{j}^{P}} \\
& \Psi^{F} \equiv \frac{P^{F}}{P_{0}^{F}} ; \Psi^{P} \equiv \frac{P^{P}}{P_{0}^{P}} ; \xi \equiv \frac{z}{L} ; P e_{j}^{F} \equiv \frac{n_{0}^{F}}{\alpha_{m} U_{j} P_{o}^{F} L} ; D a \equiv \frac{A_{C} L}{n_{o}^{F}} \\
& P_{j}^{F}=y_{j}^{F} \cdot P^{F}=\frac{x_{j}^{F}}{\sum_{j} x_{j}^{F}} P_{o}^{F} \Psi^{F} ; P_{j}^{P}=y_{j}^{P} \cdot P^{P}=\frac{x_{j}^{P}}{\sum_{j} x_{j}^{P}} P_{o}^{P} \Psi^{P} \\
& M W_{a v e}^{F}=\frac{\sum_{j} x_{j}^{F} M W_{j}}{\sum_{j} x_{j}^{F}} \\
& G^{F}=\rho^{F} u^{F}=\frac{n_{j}^{F} \sum_{j}\left(x_{j}^{F} M W_{j}\right)}{A^{F}} \\
& u^{F}=\frac{Q^{F}}{A^{F}}=\frac{n^{F} R T}{P^{F} A_{a v e}^{F}}=\frac{P_{o}^{F} \Psi^{F} \sum_{j}^{F} x_{j}^{F} M W_{j}}{R T \sum_{j} x_{j}^{F}} \\
& n_{o}^{F} R T \sum_{j} x_{j}^{F}
\end{aligned}
$$

The equations equivalent to eqs $1.7-1.10$ are

$$
-\frac{d \Psi^{F}}{d \xi}=\frac{L}{P_{o}^{F}} \frac{f^{F}\left(G_{m}^{F}\right)^{2}}{g_{c} d_{P}^{F} \rho^{F}}
$$

Feed side: $\quad \frac{d x_{j}^{F}}{d \xi}=-\frac{1}{P e_{j}^{F}}\left(\frac{x_{j}^{F}}{\sum_{j} x_{j}^{F}} \Psi^{F}-\frac{x_{j}^{P}}{\sum_{j} x_{j}^{P}} \Psi^{P}\right)+v_{j} D a \cdot r^{F}$

Permeate side: $\frac{d x_{j}^{P}}{d \xi}=\frac{1}{P e_{j}^{F}}\left(\frac{x_{j}^{F}}{\sum_{j} x_{j}^{F}} \Psi^{F}-\frac{x_{j}^{P}}{\sum_{j} x_{j}^{P}} \Psi^{P}\right)$

$$
\text { at } \xi=0, \quad \Psi^{F}=1, \quad \Psi^{\mathrm{P}}=1
$$




\section{Appendix II: Material Balance of the Mathematical Mode I Developed in this Study.}

Water gas shift reaction is as follows;

$\mathrm{CO}+\mathrm{H}_{2} \mathrm{O} \leftrightarrow \mathrm{CO}_{2}+\mathrm{H}_{2}$

Mass balance for component $\mathrm{CO}$ along the reactor for counter-current flow system is as follows,

$$
\begin{aligned}
& \frac{d\left(n_{C O}^{F}\right)}{d z}=\pi\left(R_{o}^{2}-R_{i}^{2}\right) \cdot r_{C O}-2 \pi \cdot R_{i} \cdot K_{C O}\left(p_{C O}^{F}-p_{C O}^{P}\right) \\
& \frac{d\left(n_{C O}^{P}\right)}{d z}=-2 \pi \cdot R_{i} \cdot K_{C O}\left(p_{C O}^{F}-p_{C O}^{P}\right)
\end{aligned}
$$

From (1) and (2) we obtain

$\frac{d\left(n_{C O}^{F}-n_{C O}^{P}\right)}{d z}=A_{C} \cdot r_{C O}$

Where,

$$
A_{c} \equiv \pi\left(R_{o}^{2}-R_{i}^{2}\right)
$$

Similarly, for component $\mathrm{H}_{2} \mathrm{O}, \mathrm{CO}_{2}$ and $\mathrm{H}_{2}$

$$
\begin{aligned}
& \frac{d\left(n_{\mathrm{H}_{2} \mathrm{O}}^{F}-n_{\mathrm{H}_{2} \mathrm{O}}^{P}\right)}{d z}=A_{C} \cdot r_{\mathrm{H}_{2} \mathrm{O}}=A_{C} \cdot r_{C O} \\
& \frac{d\left(n_{\mathrm{CO}_{2}}^{F}-n_{\mathrm{CO}_{2}}^{P}\right)}{d z}=A_{C} \cdot r_{\mathrm{CO}_{2}}=-A_{C} \cdot r_{C O} \\
& \frac{d\left(n_{\mathrm{H}_{2}}^{F}-n_{\mathrm{H}_{2}}^{P}\right)}{d z}=A_{C} \cdot r_{\mathrm{H}_{2}}=-A_{C} \cdot r_{C O}
\end{aligned}
$$

Add (3) and (5), we can get an equation with respect to $\mathrm{C}$

$$
\begin{aligned}
& r_{\mathrm{CO}}+r_{\mathrm{CO}_{2}}=A_{C} \cdot \frac{d\left(n_{\mathrm{CO}}^{F}+n_{\mathrm{CO}_{2}}^{F}-n_{\mathrm{CO}}^{P}-n_{\mathrm{CO}_{2}}^{P}\right)}{d z}=0 \\
& n_{\mathrm{CO}}^{F}+n_{\mathrm{CO}_{2}}^{F}-n_{\mathrm{CO}}^{P}-n_{\mathrm{CO}_{2}}^{P}=\text { const. }
\end{aligned}
$$


Similarly, with respect to $\mathrm{H}$

$r_{\mathrm{H}_{2} \mathrm{O}}+r_{\mathrm{H}_{2}}=0$

$n_{\mathrm{H}_{2} \mathrm{O}}^{F}+n_{\mathrm{H}_{2}}^{F}-n_{\mathrm{H}_{2} \mathrm{O}}^{P}-n_{\mathrm{H}_{2}}^{P}=$ const.

And $\mathrm{O}$

$r_{\mathrm{CO}}+r_{\mathrm{H}_{2} \mathrm{O}}+2 r_{\mathrm{CO}_{2}}=0$

$n_{\mathrm{CO}}^{F}+n_{\mathrm{H}_{2} \mathrm{O}}^{F}+2 n_{\mathrm{CO}_{2}}^{F}-n_{\mathrm{CO}}^{P}-n_{\mathrm{H}_{2} \mathrm{O}}^{P}-2 n_{\mathrm{CO}_{2}}^{P}=$ const.

Of course we don't need to make special forms such as (7), (9) and (11) because many expressions can be created. For example,

$(3)+(6)=0$

$(4)+(5)=0$

The following 5 graphs were obtained under the condition which is Counter-current flow system

$\mathrm{T}=250{ }^{\circ} \mathrm{C}, \mathrm{P}_{\mathrm{F}}=3 \mathrm{~atm}, \mathrm{P}_{\mathrm{P}}=1 \mathrm{~atm}, \mathrm{~W} / \mathrm{F}_{\mathrm{CO}}=12.9(\mathrm{~g}-\mathrm{cat} * \mathrm{hr} / \mathrm{gmol} \mathrm{CO})$

Rich's base case

Note that the green lines in the following graphs are exactly same. (Figure 1, 2, 3 and 4) 


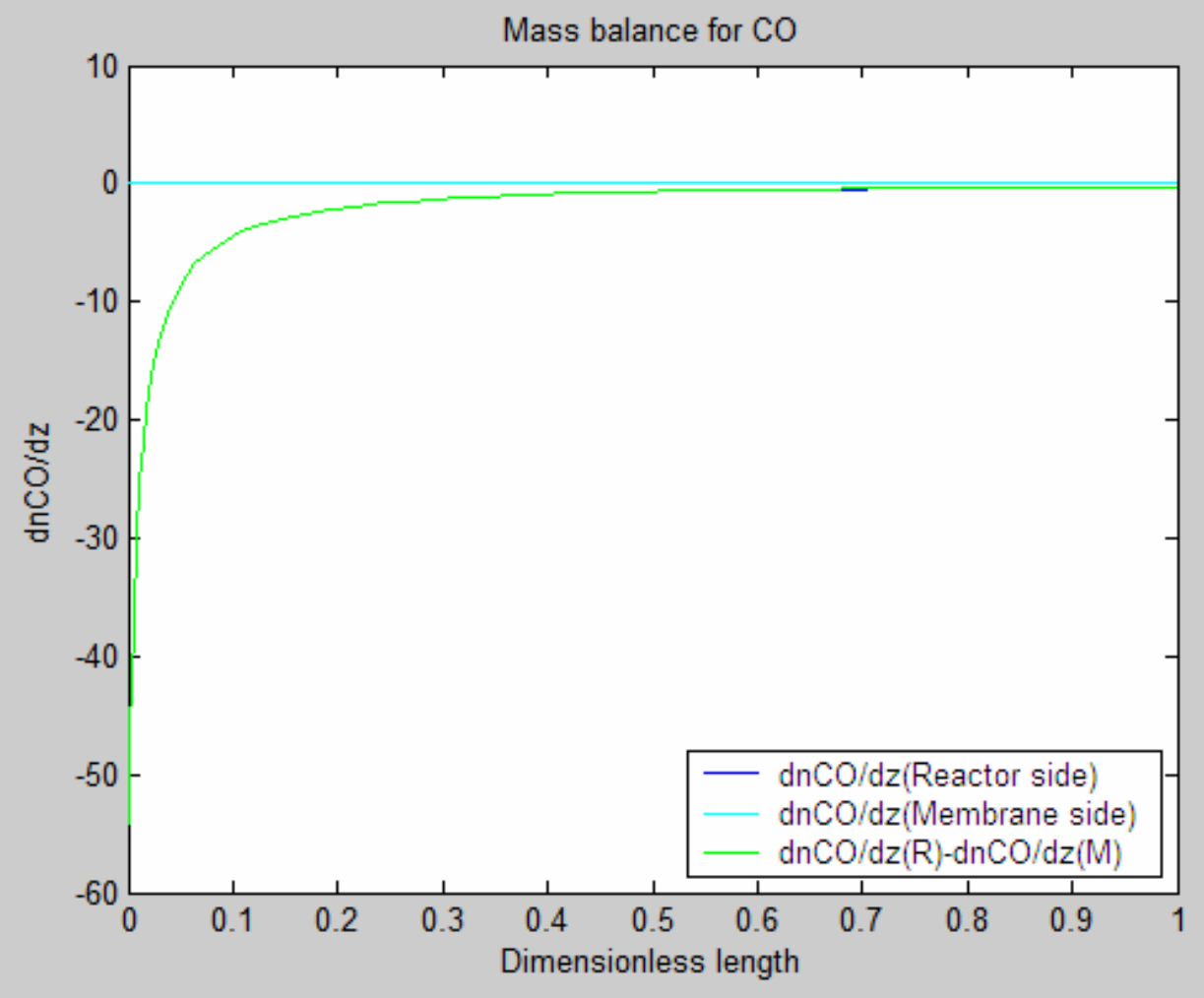

Figure $1 \frac{d n_{C O}^{F}}{d z}, \frac{d n_{C O}^{P}}{d z}, \frac{d n_{C O}^{F}-d n_{C O}^{P}}{d z}$

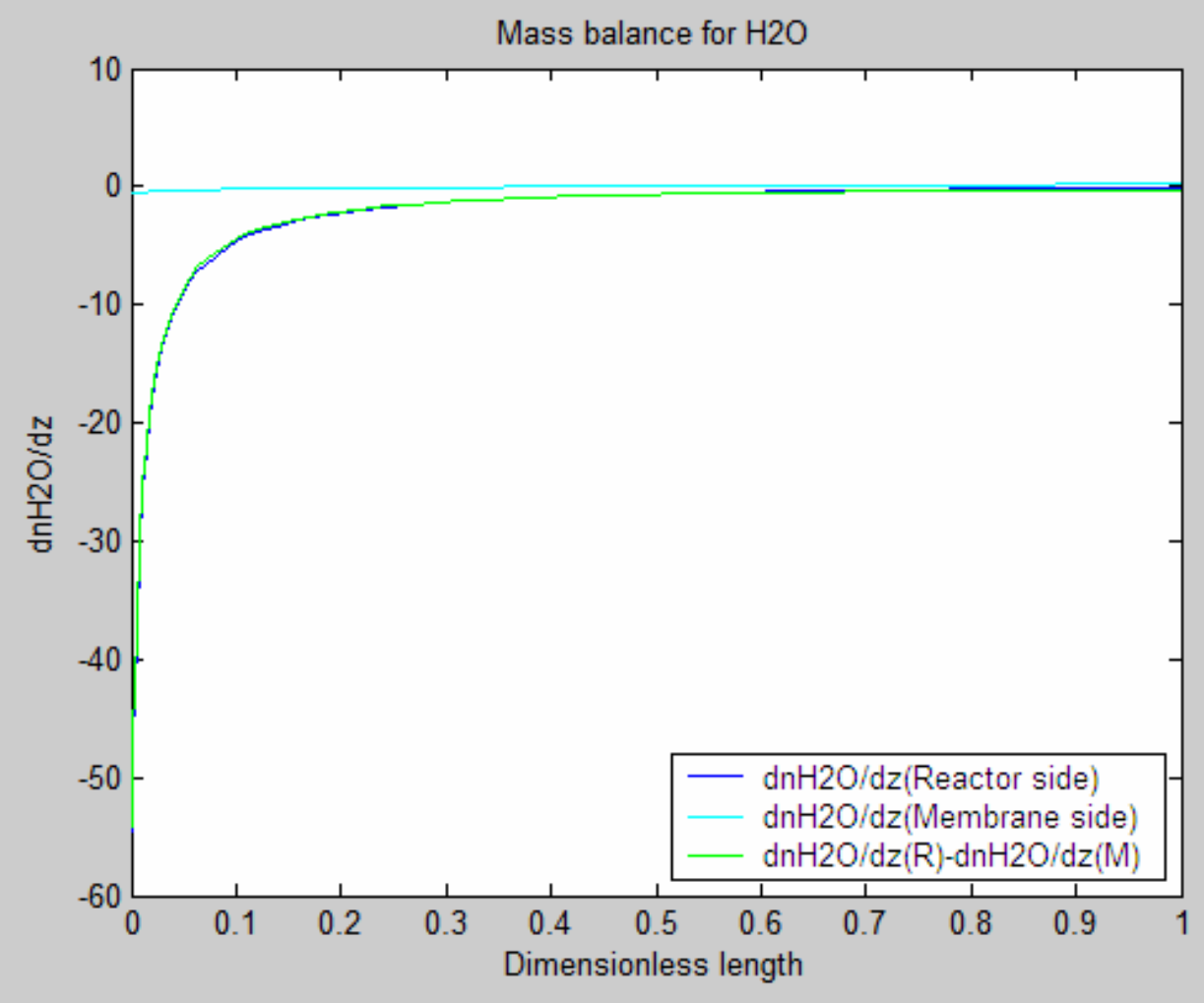

Figure $2 \frac{d n_{\mathrm{H}_{2} \mathrm{O}}^{F}}{d z}, \frac{d n_{\mathrm{H}_{2} \mathrm{O}}^{P}}{d z}, \frac{d n_{\mathrm{H}_{2} \mathrm{O}}^{F}-d n_{\mathrm{H}_{2} \mathrm{O}}^{P}}{d z}$ 


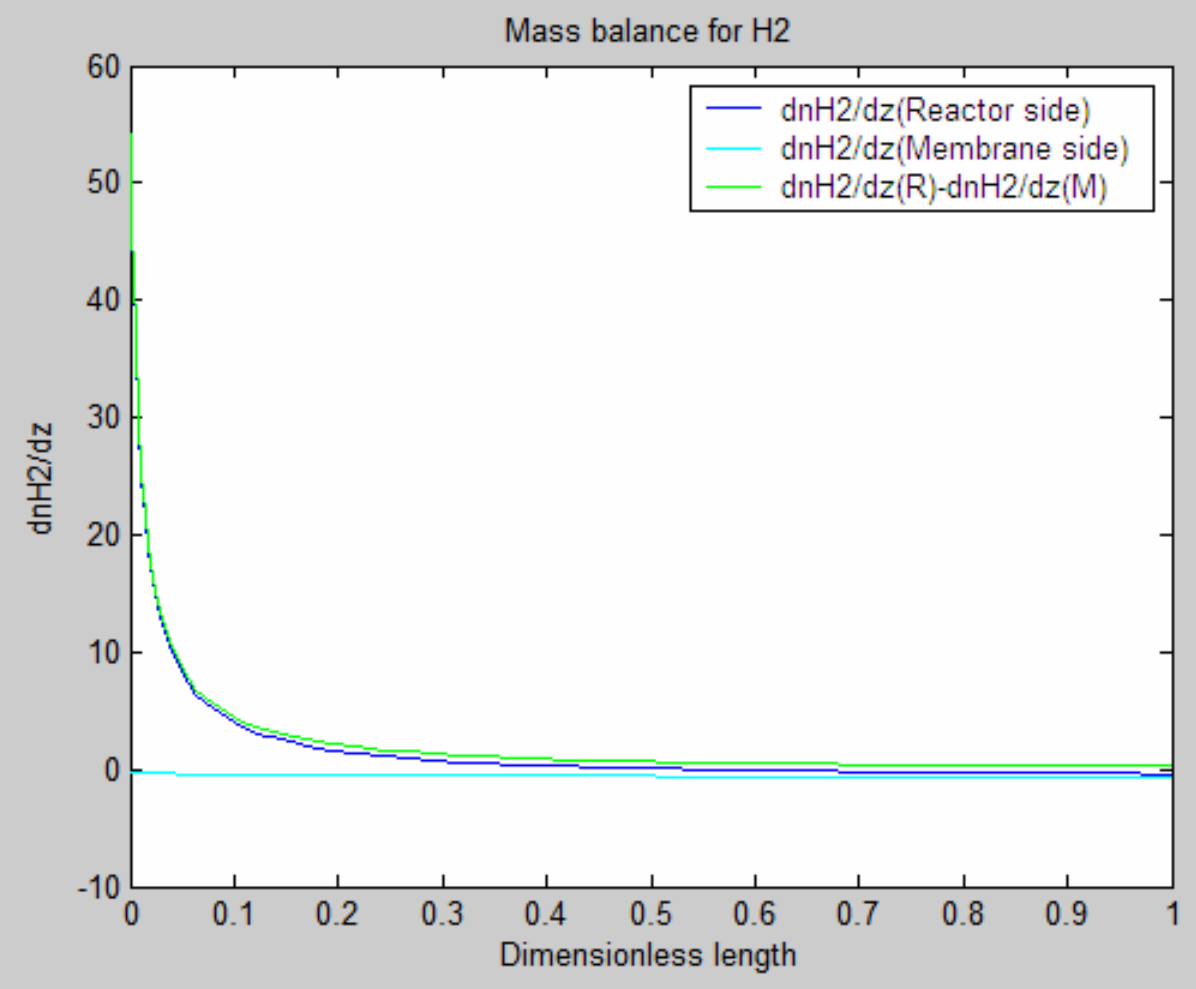

Figure $3 \frac{d n_{H_{2}}^{F}}{d z}, \frac{d n_{H_{2}}^{P}}{d z}, \frac{d n_{H_{2}}^{F}-d n_{H_{2}}^{P}}{d z}$

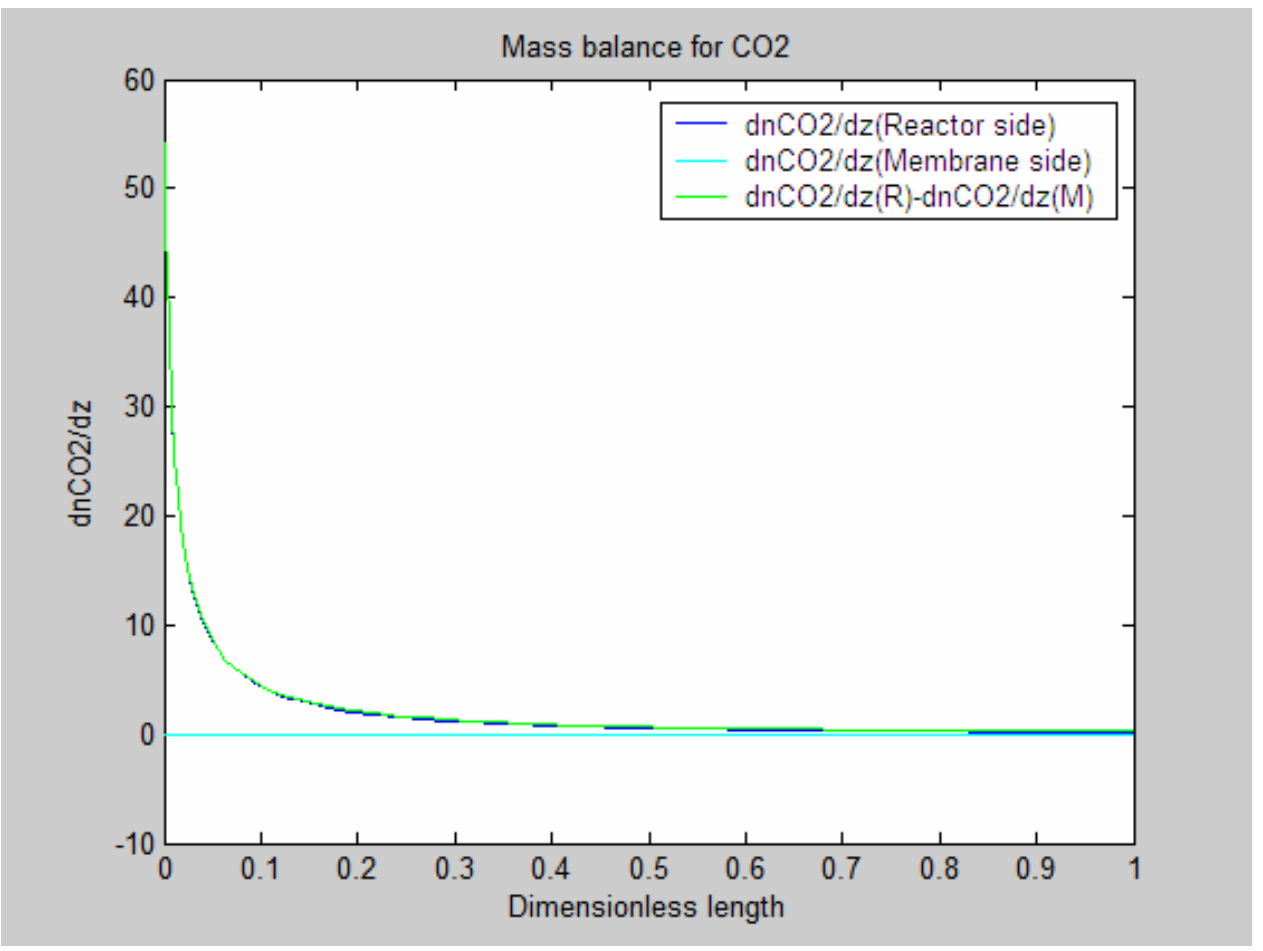

Figure $4 \frac{d n_{\mathrm{CO}_{2}}^{F}}{d z}, \frac{d n_{\mathrm{CO}_{2}}^{P}}{d z}, \frac{d n_{\mathrm{CO}_{2}}^{F}-d n_{\mathrm{CO}_{2}}^{P}}{d z}$ 


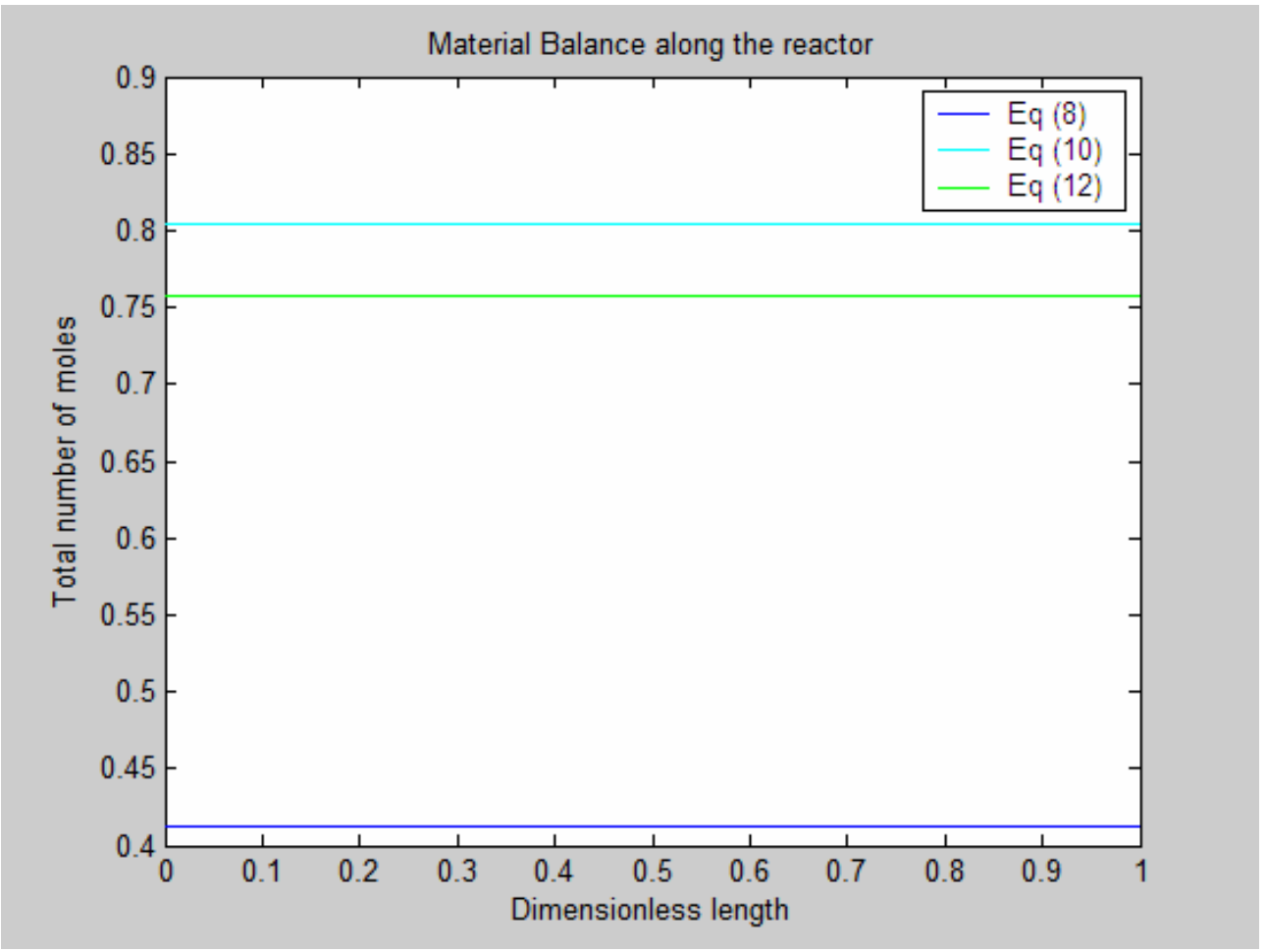

Figure 5 Eq. (8), (10) and (12) 
In case of the co-current system, the sign for the permeate side must be changed. For example, if we get the mass balance for $\mathrm{CO}$ again, it goes

$$
\begin{aligned}
& \frac{d\left(n_{C O}^{F}\right)}{d z}=A_{C} \cdot r_{C O}-2 \pi \cdot R_{i} \cdot K_{C O}\left(p_{C O}^{F}-p_{C O}^{P}\right) \\
& \frac{d\left(n_{C O}^{P}\right)}{d z}=2 \pi \cdot R_{i} \cdot K_{C O}\left(p_{C O}^{F}-p_{C O}^{P}\right)
\end{aligned}
$$

From (1) and (2) we obtain

$$
\frac{d\left(n_{C O}^{F}+n_{C O}^{P}\right)}{d z}=A_{C} \cdot r_{C O}
$$

Similarly, for component $\mathrm{H}_{2} \mathrm{O}, \mathrm{CO}_{2}$ and $\mathrm{H}_{2}$

$$
\begin{aligned}
& \frac{d\left(n_{\mathrm{H}_{2} \mathrm{O}}^{F}+n_{\mathrm{H}_{2} \mathrm{O}}^{P}\right)}{d z}=A_{C} \cdot r_{\mathrm{H}_{2} \mathrm{O}}=A_{C} \cdot r_{C O} \\
& \frac{d\left(n_{\mathrm{CO}_{2}}^{F}+n_{\mathrm{CO}_{2}}^{P}\right)}{d z}=A_{C} \cdot r_{\mathrm{CO}_{2}}=-A_{C} \cdot r_{C O} \\
& \frac{d\left(n_{\mathrm{H}_{2}}^{F}+n_{\mathrm{H}_{2}}^{P}\right)}{d z}=A_{C} \cdot r_{\mathrm{H}_{2}}=-A_{C} \cdot r_{C O}
\end{aligned}
$$

Add (3) and (5), we can get an equation with respect to $\mathrm{C}$

$$
\begin{aligned}
& r_{\mathrm{CO}}+r_{\mathrm{CO}_{2}}=A_{C} \cdot \frac{d\left(n_{\mathrm{CO}}^{F}+n_{\mathrm{CO}_{2}}^{F}+n_{C O}^{P}+n_{\mathrm{CO}_{2}}^{P}\right)}{d z}=0 \\
& n_{\mathrm{CO}}^{F}+n_{\mathrm{CO}_{2}}^{F}+n_{\mathrm{CO}}^{P}+n_{\mathrm{CO}_{2}}^{P}=\text { const. }
\end{aligned}
$$

Similarly, with respect to $\mathrm{H}$

$$
\begin{aligned}
& r_{\mathrm{H}_{2} \mathrm{O}}+r_{\mathrm{H}_{2}}=0 \\
& n_{\mathrm{H}_{2} \mathrm{O}}^{F}+n_{\mathrm{H}_{2}}^{F}+n_{\mathrm{H}_{2} \mathrm{O}}^{P}+n_{\mathrm{H}_{2}}^{P}=\text { const. }
\end{aligned}
$$

And $\mathrm{O}$

$$
r_{\mathrm{CO}}+r_{\mathrm{H}_{2} \mathrm{O}}+2 r_{\mathrm{CO}_{2}}=0
$$


$n_{\mathrm{CO}}^{F}+n_{\mathrm{H}_{2} \mathrm{O}}^{F}+2 n_{\mathrm{CO}_{2}}^{F}+n_{\mathrm{CO}}^{P}+n_{\mathrm{H}_{2} \mathrm{O}}^{P}+2 n_{\mathrm{CO}_{2}}^{P}=$ const.

Now, the following 5 graphs were obtained under the same condition described above at co-current flow system.

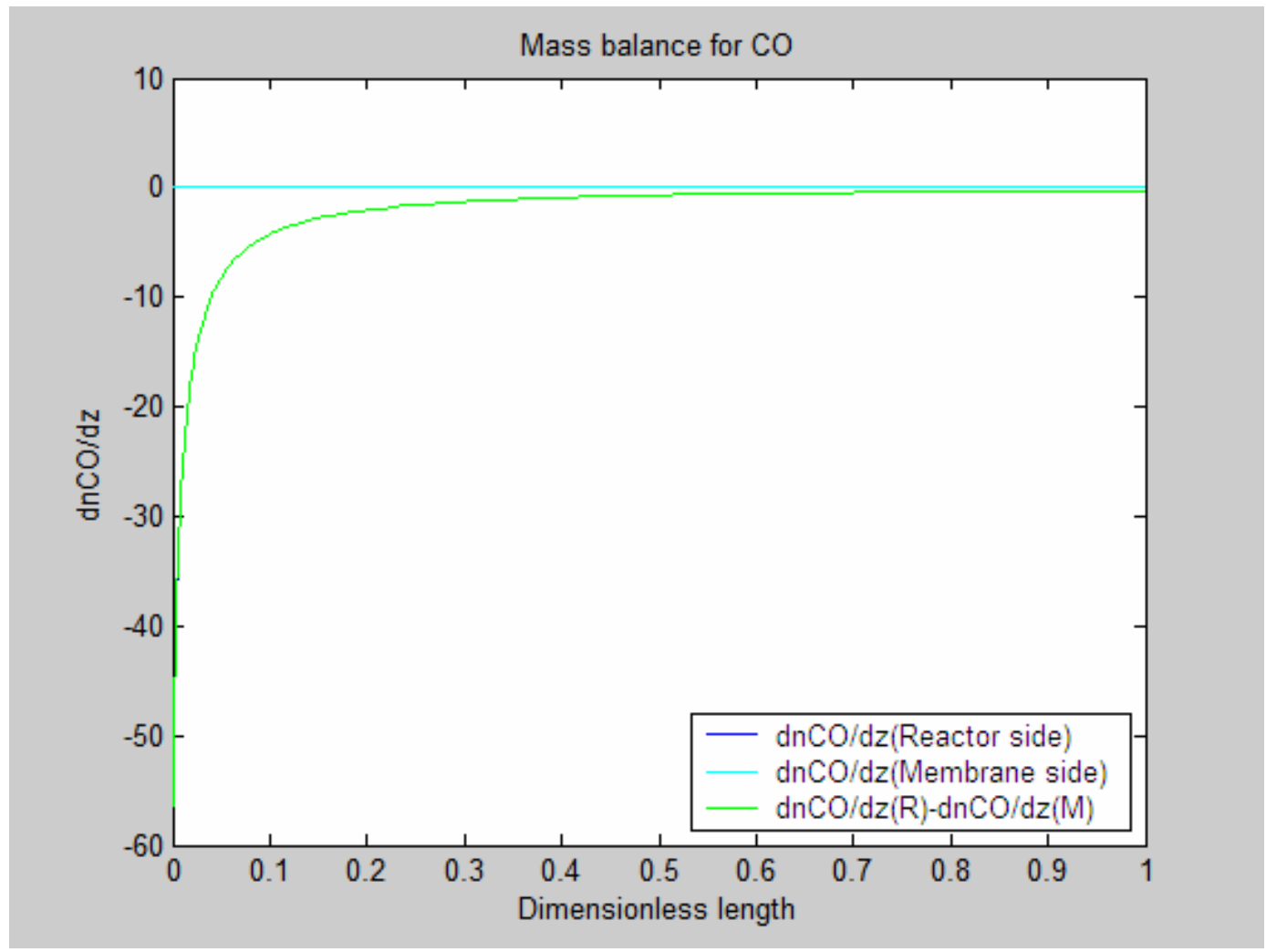

Figure $6 \frac{d n_{C O}^{F}}{d z}, \frac{d n_{C O}^{P}}{d z}, \frac{d n_{C O}^{F}+d n_{C O}^{P}}{d z}$ 


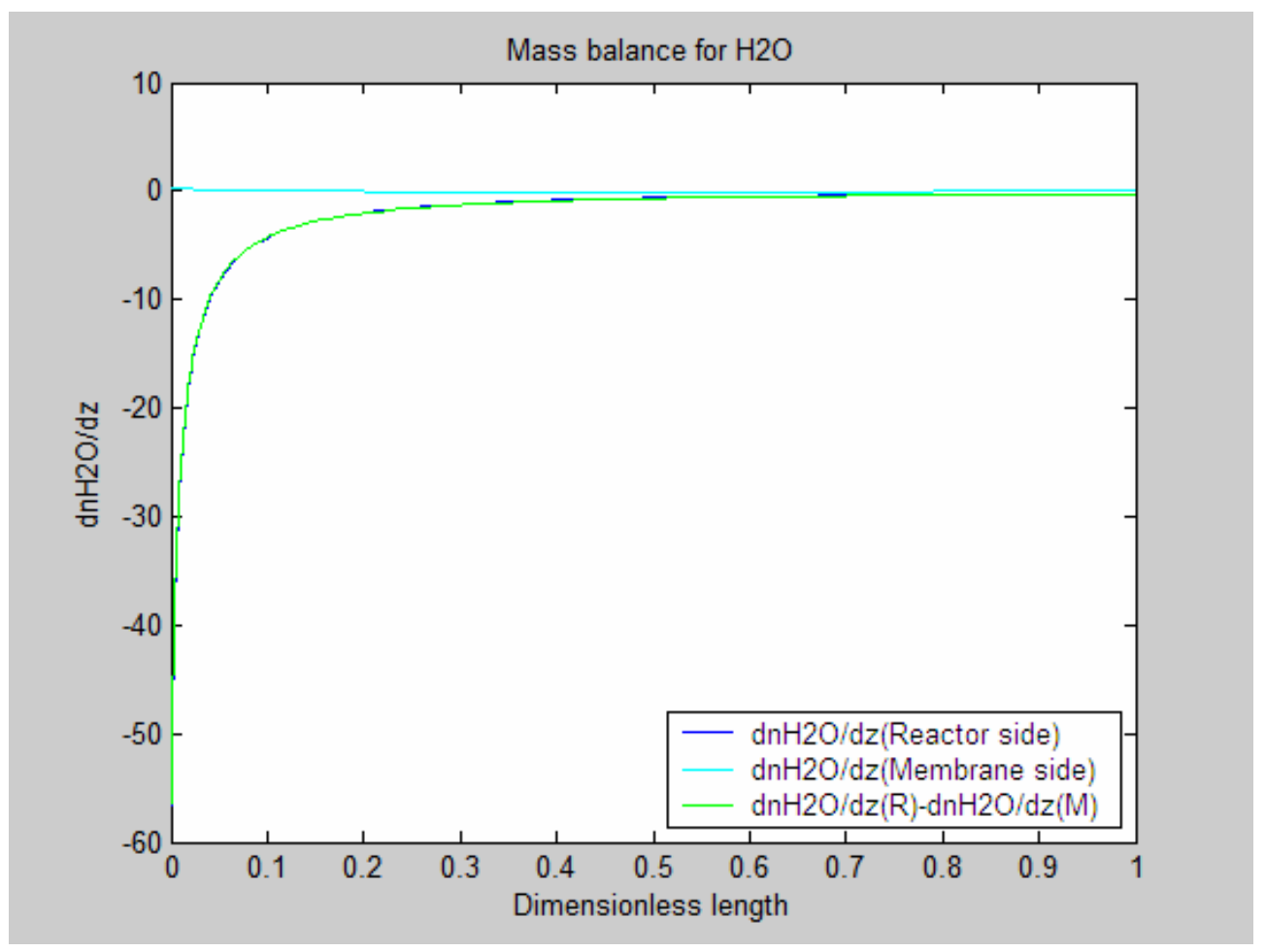

Figure $7 \frac{d n_{\mathrm{H}_{2} \mathrm{O}}^{F}}{d z}, \frac{d n_{\mathrm{H}_{2} \mathrm{O}}^{P}}{d z}, \frac{d n_{\mathrm{H}_{2} \mathrm{O}}^{F}+d n_{\mathrm{H}_{2} \mathrm{O}}^{P}}{d z}$

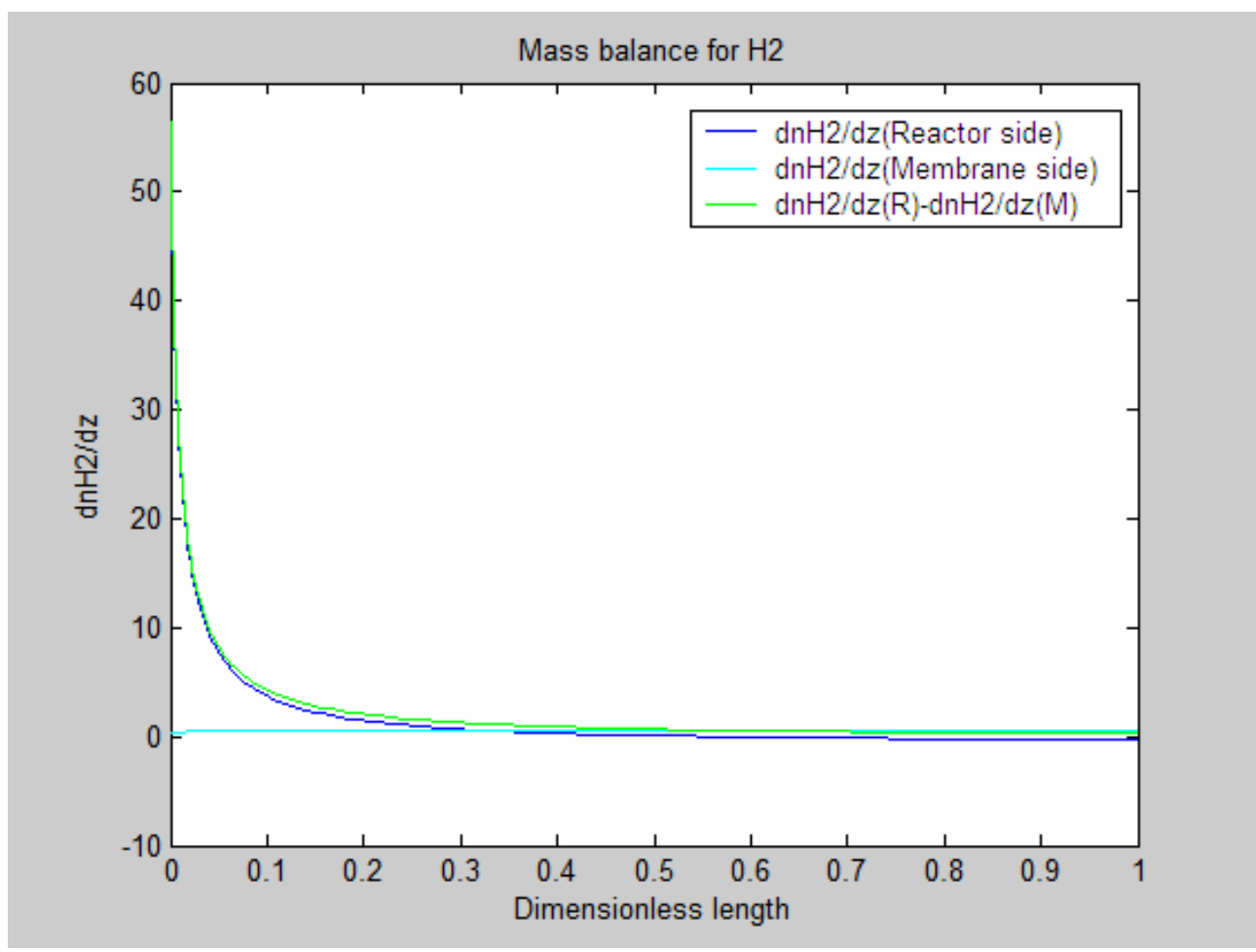

Figure $8 \frac{d n_{H_{2}}^{F}}{d z}, \frac{d n_{H_{2}}^{P}}{d z}, \frac{d n_{H_{2}}^{F}+d n_{H_{2}}^{P}}{d z}$ 


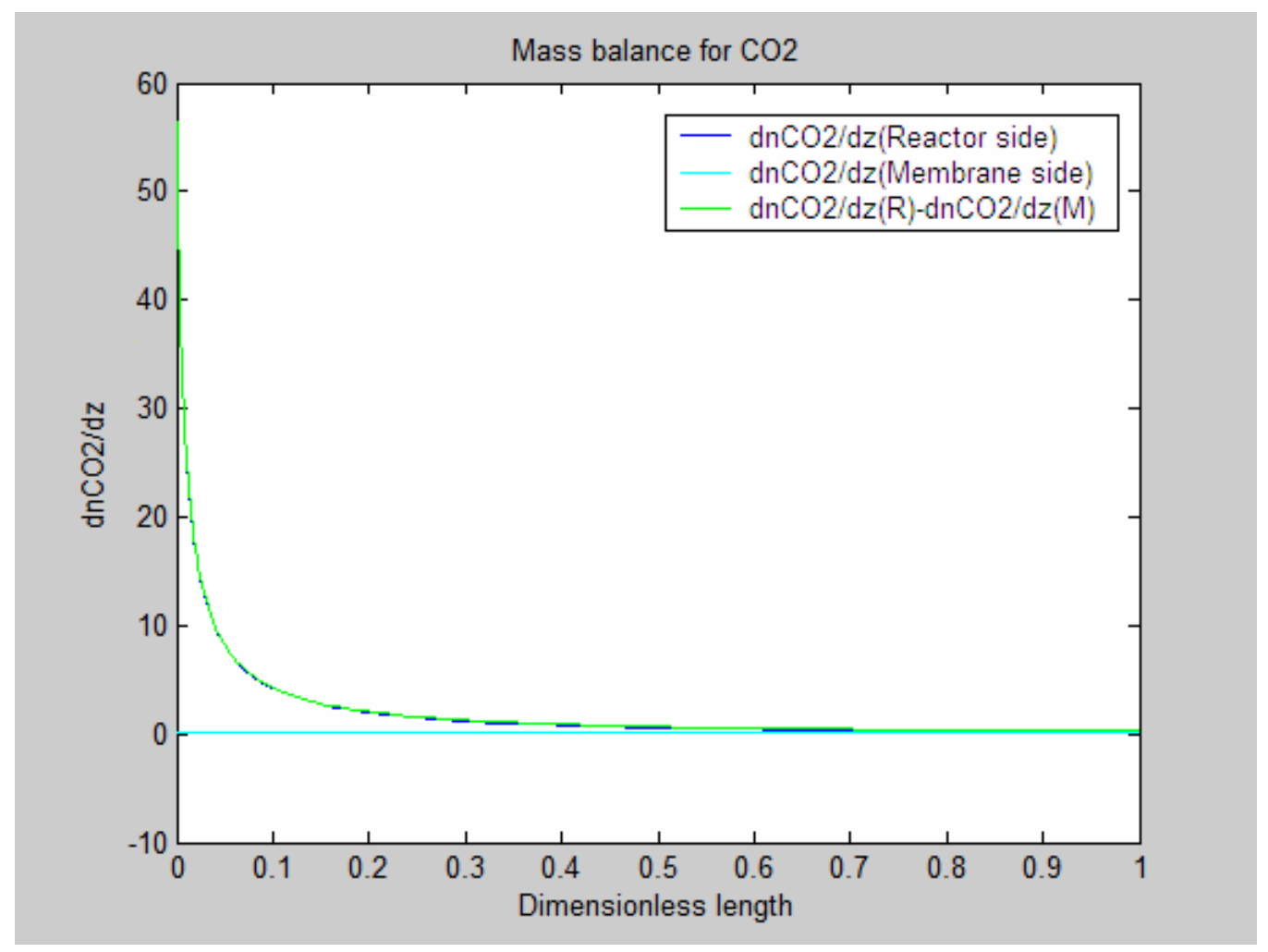

Figure $9 \frac{d n_{\mathrm{CO}_{2}}^{F}}{d z}, \frac{d n_{\mathrm{CO}_{2}}^{P}}{d z}, \frac{d n_{\mathrm{CO}_{2}}^{F}+d n_{\mathrm{CO}_{2}}^{P}}{d z}$

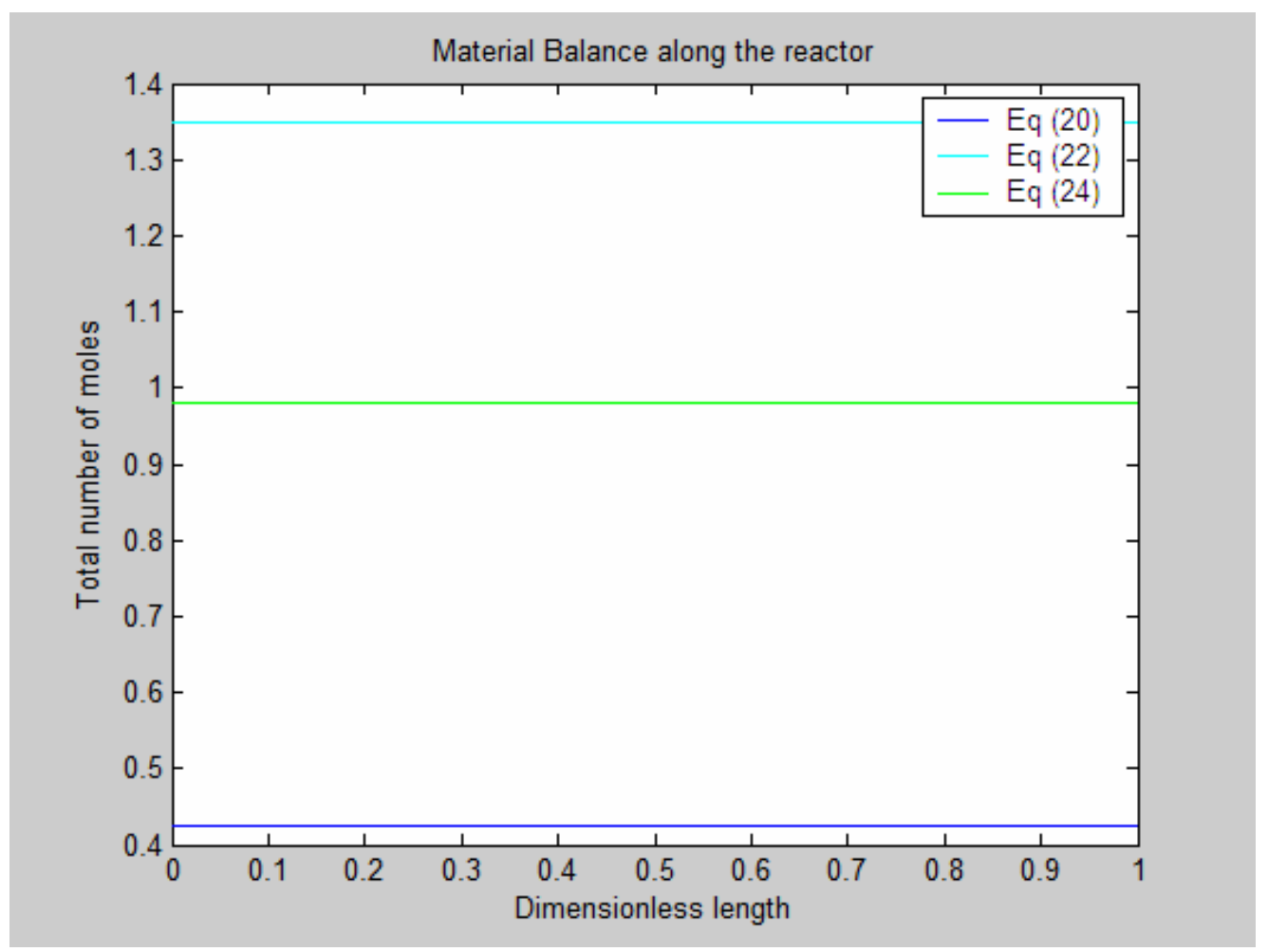

Figure 10 Eq. (20), (22) and (24) 


\section{Conclusion:}

Key conclusions drawn from the study during this period include:

- $\quad$ Single stage low-temperature-shift water-gas-shift (WGS-LTS) via a membrane reactor (MR) process was studied through both mathematical simulation and experimental verification in this period. Using the kinetic parameters experimentally obtained by us, we are able to validate the mathematical model via the bench-top experimental results.

- Although the thermodynamic conversion of CO could be as high as $\sim 90 \%$ in the LTS range, our proposed MR yields a reactor size that is 10 to $>55 \%$ smaller than the comparable conventional reactor for a CO conversion of 80 to $90 \%$. In addition, the $\mathrm{CO}$ contaminant level in the hydrogen produced via MR ranges from 1,000 to $4,000 \mathrm{ppm}$ vs 40,000 to $>70,000 \mathrm{ppm}$ via the conventional reactor. The advantages of the reduced WGS reactor size and the reduced CO contaminant level provide an excellent opportunity for intensification of the hydrogen production process by the proposed MR.

- A significant number (i.e., 98) of full-scale membrane tubes have been produced with an on-spec ratio of $>76 \%$ during this first production trial. In addition, an innovative full-scale membrane module has been designed, which can potentially deliver $>20$ to $30 \mathrm{~m}^{2} /$ module making it suitable for large-scale applications, such as power generation.

- Our membrane performance and stability were verified in a refinery pilot testing facility on a hydrocracker purge gas. No change in membrane performance was noted over the $>100 \mathrm{hrs}$ of testing conducted in the presence of $>30 \% \mathrm{H}_{2} \mathrm{~S}$, $>5,000 \mathrm{ppm} \mathrm{NH}_{3}$ (estimated), and heavy hydrocarbons on the order of $25 \%$. The high stability of these membranes opens the door for the use of our membrane in the WGS environment with significantly reduced pretreatment burden.

We have also worked on (i) thermal management for the proposed one-stage WGS reactor, and (ii) defining and planning the field test in Year III at the PFDU facility. These results will be reported in the next report. 


\section{Literature Cited:}

1. C. V. Ovesen, et. al. "A Microkinetic Analysis of the Water-Gas Shift Reaction under Industrial Conditions", Journal of Catalysis 158, 170-180 (1996) 


\section{List of Acronyms:}

LTS: low temperature shift

WGS: water gas shift reaction

MR: membrane reactor

PFR: packed fixed-bed reactor

Ea: activation energy 